The abstracts (Nephron Physiol 2006;104:p33-p54) are only available online, free of charge, under www.karger.com/doi/10.1159/000093286

\title{
Takis Anagnostopoulos Symposium: Renal and Epithelial Physiology and Pathophysiology
}

June 16-17, 2005, Paris

\section{Abstracts and Minireviews}

Guest Editors

Gabrielle Planelles, Paris

Aleksander Edelman, Paris

Contents

Abstracts

Author Index for Abstracts

Minireviews based on Invited Lectures 
1

\section{Site and Mechanism of Ascites and Sodium Retention in Cirrhotic Mice}

\author{
D. Ackermann, B. Vogt, M. Imbert-Teboul, L. Cheval, \\ A. Doucet \\ CNRS-UPMC UMR7134, Physiologie et Génomique \\ Rénales, Institut des Cordeliers, 15 rue de l'Ecole de \\ Médecine, Paris Cedex 06, France
}

The renal site of sodium retention in liver cirrhosis and the role of aldosterone are not clearly established as yet. In this study, we addressed these questions in a mouse model of liver cirrhosis. In a first series of experiments, CD1 mice underwent bile duct ligation (BDL) or sham operation (sham), and their renal sodium handling was evaluated daily in metabolic cages over a 3 to 4 -week period. At the end of this period, $\sim 30 \%$ of BDL mice displayed ascites $(\sim 1 \mathrm{ml}$, $\left.\mathrm{BDL}^{+}\right)$whether the remaining ones did not $\left(\mathrm{BDL}^{-}\right)$. Starting 2 weeks post BDL, cumulative daily sodium balance increased more rapidly in $\mathrm{BDL}^{+}$as compared to sham mice. In $\mathrm{BDL}^{+}$mice, Na,K-ATPase activity was reduced by $30 \%$ and $70 \%$ in proximal convoluted and straight tubules respectively, and was increased over 7-fold in cortical collecting ducts (CCD). No change in Na,K-ATPase was observed in other nephron segments, including connecting tubules and outer medullary collecting ducts, two targets of aldosterone. Abundance of $\mathrm{ENaC}$ and $\mathrm{Na}, \mathrm{K}$-ATPase subunit mRNAs was increased 7- to 135fold in $\mathrm{CCDs}$ from $\mathrm{BDL}^{+}$mice. $\mathrm{BDL}^{-}$mice were intermediate between sham and $\mathrm{BDL}^{+}$for all parameters. Because $24 \mathrm{~h}$ urinary excretion of aldosterone and sgk mRNAs in CCD were increased 5and 35 -fold respectively in $\mathrm{BDL}^{+}$vs. sham mice, we evaluated in a second experimental series the role of hyperaldosteronemia on sodium retention and induction of Na,K-ATPase in cirrhotic mice. For this purpose, mice were adrenalectomized 10 days after BDL or sham and complemented for 3-4 weeks with physiological doses of glucoand mineralocorticoids via osmotic minipumps (corticosteroid-clamp (CC)). CC in BDL mice induced a $\sim 50 \%$ death rate, but $\sim 20 \%$ of surviving mice displayed ascites. $\mathrm{CC}-\mathrm{BDL}^{+}$also displayed increased $\mathrm{Na}$,K-ATPase activity in CCD as compared to CC-sham mice. It is concluded that renal sodium retention in liver cirrhosis originates from CCDs and is independent of hyperaldosteronemia.

\section{2}

\section{The Renal $\mathrm{Na}^{+} /$Phosphate Cotransporter NaPi-lla Is Internalized via the Receptor-Mediated Endocytic Route in Response to Parathyroid Hormone}

\author{
D. Bacic ${ }^{1,2}$, M. LeHir' ${ }^{2}$ J. Biber' ${ }^{1}$, B. Kaissling ${ }^{2}$, \\ C.A. Wagner ${ }^{1}, H$. Murer ${ }^{1}$ \\ ${ }^{1}$ Institute of Anatomy, ${ }^{2}$ Institute of Physiology, \\ Winterthurerstrasse, Zurich, Switzerland
}

PTH induces the acute internalization of the major renal $\mathrm{Na}^{+} /$phosphate cotransporter NaPi-IIa from the brush border membrane (BBM) and its routing to and subsequent degradation in lysosomes. Previous work indicated that megalin, part of the apical receptor-mediated endocytic apparatus may play a role in the PTHinduced removal of NaPi-IIa. Here we examined the time-dependent internalization of NaPi-IIa after acute PTH application using immunohistochemistry and markers of several endocytic compartments. NaPi-IIa removal from the BBM was detectable as early as 5 min after PTH injection. After 10-15 min NaPi-IIa was localized in subapical compartments staining also for clathrin. Shortly thereafter NaPi-IIa appeared in endosomes positive for early endosome antigen 1 (EEA1). After 45-60 min, NaPi-IIa was found in late endosomes/ lysosomes marked with lgp120. In contrast, no change in the subcellular localization of megalin and the $\mathrm{Na}^{+} / \mathrm{H}^{+}$-exchanger NHE3 at the level of immunohistochemistry and light microscopy was detected up to $60 \mathrm{~min}$ after PTH injection. To further characterize the internalization route, insulin and horse-radish peroxidase (HRP) as markers for receptor-mediated and fluid-phase mediated endocytosis, respectively, were used. NaPi-IIa colocalized with insulin 5-30 min after PTH injection but did not overlap with HRP. These results demonstrate a distinct internalization route of NaPi-IIa in response to PTH application that may involve the receptor-mediated endocytic pathway including clathrin-coated vesicles, early endosomes, and eventually routes $\mathrm{NaPi}$-IIa to lysosomes for degradation. Loss of megalin, as previously described, may impair this pathway. Since, after injection of PTH megalin could not be detected in clathrin or EEA1-positive compartments, we suggest that potential interactions between megalin and $\mathrm{NaPi}$-IIa may have occurred at an earlier time point during internalization.

\begin{tabular}{|c|c|}
\hline KARGER & $\begin{array}{l}\text { (C) } 2006 \text { S. Karger AG, Basel } \\
1660-2137 / 06 / 1041-0034 / \$ 23.50 / 0\end{array}$ \\
\hline $\begin{array}{l}\text { Fax +4161306 } 1234 \\
\text { E-Mail Karger@karger.ch } \\
\text { www.karger.com }\end{array}$ & $\begin{array}{l}\text { Accessible online at: } \\
\text { www.karger.com/nep }\end{array}$ \\
\hline
\end{tabular}




\section{3 \\ Intra-Renal Arterial Injection of Autologous Mesenchymal Stem Cells in an Ovine Model of Ischemia Reperfusion}

\author{
L. Behr, M. Hekmati, G. Fromont, N. Borenstein, \\ M. Lelièvre-Pégorier, K. Laborde \\ INSERM U652, Institut Biomédical des Cordeliers, 15 rue \\ de l’Ecole de Médecine, 75270 Paris Cedex 06, France
}

The aim of this study was (1) to investigate injection into the renal artery as a new route of delivery for stem cell transplantation into kidney in an ovine model of ischemia reperfusion (IR) and (2) to assess if delay between injury and transplantation had an influence on the graft's yield.

Autologous cultured Mesenchymal Stem Cells (MSCs) were transplanted in control animals and animals submitted to IR. Sheep with IR were grafted at different times after damage. Renal injury was performed by percutaneous transluminal placement of a balloon catheter in the renal artery. Ischemia was assessed by morphological analysis of the kidney, HSP-72 expression and renin activity determination in the renal vein. MSCs were isolated from bone marrow, cultured, labelled and injected into the renal artery.

Results: All ewes showed renal engraftment by MSCs, both in tubules and glomeruli. MSCs expressed tubular epithelial cell markers and a podocyte phenotype. There was a significant increase of engraftment of tubules by MSCs and decreased cellular stress expression when cells were injected early after injury indicating that the delay for cell transplantation after damage should be short.

This is the first report of intra arterial autologous transplantation of MSCs in the kidney, resulting in successful engraftment and differentiation into tubular and glomerular cells. The results strongly suggest that the therapeutic window for stem cell therapy is within the early phase of the damage.

\section{4 \\ Cadmium Induces Chloride Currents in Primary Cultures of Mouse Proximal Tubules: Implications for CFTR \\ R. Belfodil, S. L'Hoste, I. Rubera, S. Soultan, C. Poujeol, M. Tauc, P. Poujeol \\ Laboratoire de Physiologie Cellulaire et Moléculaire CNRS-UMR 6548 Université de Nice Sophia-Antipolis Parc Valrose 06108 Nice Cedex 02, France}

The aim of the present study was to investigate the role of cadmium in the control of $\mathrm{Cl}^{-}$conductances along the different segments of the mouse nephron. Whole cell $\mathrm{Cl}^{-}$conductances were recorded in primary cultures of proximal convoluted tubule (PCT) and distal convoluted tubule (DCT) segments obtained by microdissection of kidney cortex from wild-type $c f t r+/+$ and $c f t r-/-$ mice.

In cells from $c f t r+/+$ mice, the application of low concentrations of cadmium $(5 \mu \mathrm{M})$ activated linear $\mathrm{Cl}^{-}$currents within 5-8 min. These currents were blocked by NPPB, glibenclamide and iodide but insensitive to DIDS $(1 \mathrm{mM})$. These characteristics were similar to those of $\mathrm{CFTR}^{-} \mathrm{Cl}^{-}$currents. Interestingly, in cells from $c f t r-/-$ mice, the addition of cadmium $\left(\mathrm{Cd}^{++}\right)$was inefficient in increasing $\mathrm{Cl}^{-}$conductances.
The $\mathrm{Cd}^{++}$- activated $\mathrm{Cl}^{-}$currents were inhibited when the cells were incubated with PD98059 (inhibitor of ERK1/2) for 20 min prior to the recording. By contrast they were insensitive to H-89 (inhibitor of PKA). Parallel studies indicated that the addition of $5 \mu \mathrm{M} \mathrm{Cd}^{++}$ increased ERK1/2 phosphorylation within $8 \mathrm{~min}$.

Taken together, these results suggested that ERK1/2 activation could be required for the stimulation of $\mathrm{Cl}^{-}$currents by acute application of cadmium.

In conclusion, we clearly demonstrated that the channel involved in the $\mathrm{Cl}^{-}$currents activated by cadmium in PCT and DCT cells could be the small-conductance CFTR $\mathrm{Cl}^{-}$channel. The involvement of ERK1/2 signalling cascade in this stimulation suggests that ERK kinase could phosphorylate CFTR.

\section{5}

\section{Down-Regulation of the Anti-Inflammatory Annexin A1 in cftrtm1Unc Mice and Cystic Fibrosis Patients}

\author{
N. Bensalem', A.P. Ventura', B. Vallée1, J. Lipecka1, \\ D. Tondelier ${ }^{1}$, N. Davezac ${ }^{1}$, A. Fajac ${ }^{3}$, I. Sermet- \\ Gaudelus $^{1,4}$, F. Halgand ${ }^{2}$, O. Laprévote ${ }^{2}$, A. Edelman ${ }^{1}$ \\ 'INSERM U467, Faculté de médecine Necker-Enfants \\ Malades, Université René Descartes, ${ }^{2}$ Laboratoire de \\ spectrométrie de masse, Institut de Chimie des \\ Substances Naturelles CNRS, Gif-sur-Yvette, ${ }^{3}$ Service \\ d'Histologie-Biologie Tumorale, UPRES EA 3499, Hôpital \\ Tenon, ${ }^{4}$ Service de Pédiatrie Générale, Hôpital Necker- \\ Enfants Malades, Paris, France
}

Clinical studies suggest that the symptomatology of Cystic Fibrosis (CF) is not only due to the abnormal CFTR-related fluid transport, but may also involve polymorphism of modifier genes and epigenic factors that remain to be identified. We applied a proteomic approach (bi-dimensional electrophoresis and mass spectrometry) to identify the differentially expressed proteins in distal colon crypts from two types of mice having the same genetic background: $\mathrm{CF}$ $c f t r^{t m 1 U n c}$ mice ( $c f t r^{-/-}$) vs. control mice (C57BL6). We analysed the proteins from colonic crypts, since it is the major site of the functional defect of CFTR in these $c f t r^{-1-}$ mice.

We focused our study on one of the proteins that was absent in control mice. The corresponding protein spot (PI 7, MW $37 \mathrm{kDa}$ ) was identified by MALDI-ToF mass spectrometry as Annexin A1 (A1), an anti-inflammatory protein (Perretti et al., News Physiol Sci 2002, pp 60-4). The immunohistochemistry experiments on mouse colon, lung, pancreas and skeletal muscle using anti-A1 antibodies showed that diminished expression of A1 is limited to CFTR-expressing tissues (colon, lung and pancreas). Absence of this inhibitory mediator of the host inflammatory response was associated with colonic upregulation of the pro-inflammatory cytosolic phospholipase $\mathrm{A}_{2}$, the precursor of the prostaglandins and leukotrienes synthesis. More importantly, A1 was strongly down-regulated (immunohistochemically) in nasal epithelial cells from six CF patients bearing a homozygous nonsense mutation Y122X in the CFTR gene.

These results suggest that A1 may be a key protein involved in $\mathrm{CF}$ pathogenesis, especially in relation to the poorly defined field of inflammation in CF. 


\section{6}

\section{Sodium Self-Inhibition of Epithelial Sodium Channel: Properties of the Extracellular $\mathrm{Na}^{+}$ Sensing Site}

V. Bize, J.-D. Horisberger

Département de Pharmacologie et de Toxicologie de I'Université de Lausanne, Lausanne, Switzerland

The epithelial sodium channel $(\mathrm{ENaC})$ is a key component of the transepithelial $\mathrm{Na}^{+}$transport, responsible for the maintenance of the sodium balance (that controls extracellular fluid volume and arterial blood pressure) and for the regulation of the surface fluid layer in airway epithelia. The open probability of $\mathrm{ENaC}$ is highly variable and seems to be dependent on the membrane potential and on the extracellular $\mathrm{Na}^{+}$concentration, a phenomenon called ' $\mathrm{Na}^{+}$self inhibition': extracellular $\mathrm{Na}^{+}$induces a decrease of the open probability of the channel and thus affects the rate of transepithelial $\mathrm{Na}^{+}$transport with a fast time course $(\sim 1-2 \mathrm{~s})$. The aim of our study is the determination of the properties of the extracellular $\mathrm{Na}^{+}$sensing site (ionic selectivity and affinity). The approach we use is to measure amiloride-sensitive $\mathrm{Na}^{+}$ currents in Xenopus laevis oocytes expressing human or Xenopus $\mathrm{ENaC}$, and loaded with $\mathrm{Na}^{+}$(an intracellular concentration of about 50 to $80 \mathrm{mM}$ ). The effects of test solutions containing different cations were measured for potentials between -100 and $+50 \mathrm{mV}$. Outward amiloride-sensitive currents recorded at $+50 \mathrm{mV}$ were inhibited by $\mathrm{Na}^{+}$or $\mathrm{Li}^{+}$(a 4-fold decrease for $\mathrm{hENaC}$ and a 10-fold decrease for XENaC at $100 \mathrm{mM} \mathrm{Na}^{+}$or $\mathrm{Li}^{+}$) compared to NMDG or a cation free solution (saccharose $180 \mathrm{mM}$ ). For $\mathrm{Na}^{+}$, this inhibition appeared to involve two binding sites: a first one with a very high affinity (the $\mathrm{K}_{\mathrm{I}}<$ $1 \mathrm{mM}, \sim 70 \%)$ and a second one with a lower affinity $\left(\mathrm{K}_{\mathrm{I}}\right.$ of $\sim 100 \mathrm{mM}$, $\sim 30 \%$ ). $\mathrm{K}^{+}$also produced a $\sim 50 \%$ inhibition of human and Xenopus $\mathrm{ENaC}$ at $100 \mathrm{mM}$. Our data suggest that one $\mathrm{Na}^{+}$ion is always bound to $\mathrm{ENaC}$ under physiological conditions and a second low affinity site is responsible for the regulatory ' $\mathrm{Na}^{+}$self inhibition' phenomenon.

Supported by the Swiss National Fund grants \# 250329-101467.

\section{7}

\section{Evidence that the Inhibitory Effect of Magnesium (Mg) on Renal Calcium (Ca) Reabsorption in Thick Ascending Limb (TAL) Is Mediated by the Calcium Sensing Receptor (CaSR)}

\section{A. Blanchard ${ }^{1,2,3}$, M. Briet ${ }^{1,2,3}$, M. Filali ${ }^{2,4}$, M. Froissart Fi, $^{1,3}$, $X$. Jeunemaitre ${ }^{2,4}$, P. Houillier $r^{1,2,3}$ \\ ${ }^{1}$ U652, INSERM, ${ }^{2}$ Paris Descartes University, ${ }^{3}$ Department of Physiology, ${ }^{4}$ Department of Molecular Genetics, HEGP, Paris, France}

Hypermagnesemia inhibits renal $\mathrm{Ca}$ reabsorption in the thick limb, but it remains to be established whether variations in serum $[\mathrm{Mg}](\mathrm{s}[\mathrm{Mg}])$ are sensed by CaSR or directly by the paracellular pathway to $\mathrm{Ca} / \mathrm{Mg}$. To address the contribution of CaSR, we studied the calciuric response to $\mathrm{Mg}$ infusion in patients with heterozygous activating $(\mathrm{n}=3, \mathrm{ADH})$ or inactivating $(\mathrm{n}=1, \mathrm{FBH})$ mutations in the
CASR gene, in 3 patients with extrarenal hypomagnesemia (ERH) and 3 healthy subjects $(\mathrm{CT})$. Before $\mathrm{Mg}$ infusion, $\mathrm{FECa}$ in $\mathrm{ADH}$ was higher than in CT $(5.1 \pm 4.4$ vs. $0.8 \pm 0.2 \%, \mathrm{p}<0.05)$ in spite of lower $\mathrm{s}[\mathrm{Ca}]$ and $\mathrm{s}[\mathrm{Mg}]$. Mg infusion increased FECa and the relationship between $\mathrm{FECa}$ and $\mathrm{s}[\mathrm{Mg}]$ was shifted to the left showing an increased sensitivity to $\mathrm{s}[\mathrm{Mg}]$ in $\mathrm{ADH}$. FBH had normal $\mathrm{s}[\mathrm{Mg}]$ and high $\mathrm{s}[\mathrm{Ca}]$. In $\mathrm{ERH}$, low $\mathrm{s}[\mathrm{Mg}]$ was associated with low $\mathrm{s}[\mathrm{Ca}]$. Baseline FECa in FBH $(0.4 \%)$ and ERH $(0.3 \pm 0.4 \%, \mathrm{p}<0.05$ vs. $\mathrm{CT}$ ) was lower than in CT. In these subjects, $\mathrm{Mg}$ infusion only weakly increased FECa and the relationship between FECa and $[\mathrm{Mg}]$ was shifted to the right as compared to CT, showing lower sensitivity to $\mathrm{s}[\mathrm{Mg}]$. Data in ERH demonstrate that higher sensitivity of ADH subjects to $\mathrm{Mg}$ was not due to chronic hypocalcemia or $\mathrm{Mg}$ depletion. These results suggest, first, that CaSR directly controls paracellular permeability to calcium in human TAL; second, that correction of hypomagnesemia (as that of hypocalcemia) might increase the renal leak of $\mathrm{Ca}$ and in turn the risk of nephrocalcinosis in $\mathrm{ADH}$.

8

\section{Localization of CFTR in Membrane Lipid Microdomains of Epithelial Cells}

F. Borot, A. Hinzpeter, F. Brouillard, N. Bensalem,

D. Tondelier, J. Fritsch, A. Edelman, M. Ollero

Université René Descartes-Paris 05, INSERM U467,

Faculté de Médecine Necker, Paris, France

Membrane lipid microdomains known as rafts facilitate protein interactions and are involved in the regulation of cell signaling processes. We hypothesize that the distribution of the chloride channel cystic fibrosis transmembrane regulator (CFTR) among different membrane microdomains may determine its interactions with other proteins and lipids which in turn would modulate its function. As a consequence, altered localization of CFTR due to gene mutations could be involved in the pathogenesis of cystic fibrosis. We studied the microdomain distribution of CFTR, in basal and proinflammatory conditions, in the human airway epithelial cell line Calu-3 and in mouse pancreas acinarduct cells, both endogenously expressing the channel. Cells were lysed in the presence of $1 \%$ Triton X-100, and the soluble (non-raft) and insoluble (raft) fractions separated by a discontinuous sucrose gradient, and the presence of CFTR detected by western blotting. The results show that CFTR is mainly localized to non-rafts, while a significant part (around 9\%, as determined by densitometry) is present in rafts. This was confirmed when only surface biotinylated proteins where analyzed (around 30\% in rafts). Similar results where obtained in mouse pancreatic cells. When Calu-3 cells where treated with 2 and $3.5 \mathrm{ng} / \mathrm{mL}$ of the pro-inflammatory cytokine IL- $1 \beta$, a dose-dependent displacement of biotinylated CFTR towards non-raft domains was observed. To test for potential differences in lateral distribution of proteins in the presence and absence of functional CFTR, we analyzed the localization of the chloride channel CLC-2 in pancreatic acinar-duct cells from wild-type and CFTR-knockout mice. Equivalent amounts of CLC-2 were found in rafts and non-rafts in wild-type cells, but no signal was obtained in rafts from knockout cells. Taken together, these results suggest that (i) CFTR is unevenly distributed among membrane microdomains, (ii) its distribution is altered by a pro-inflammatory stimulus, and (iii) the lateral distribution of membrane proteins may be altered in cystic fibrosis as a result of CFTR dysfunction. 


\section{9}

\section{Blue Native-SDS PAGE Analysis of Membrane Proteins From Colonic Crypts Reveals Reduced Expression of the mCICA3 Protein in Cystic Fibrosis Knock-Out Mice}

\author{
F. Brouillard ${ }^{1}$, N. Bensalem ${ }^{1}$, A. Hinzpeter ${ }^{1}$, D. Tondelier ${ }^{1}$, \\ A.D. Gruber ${ }^{2}$, M. Ollero', A. Edelman ${ }^{1}$ \\ ${ }^{1}$ INSERM U467, 156 rue de Vaugirard Paris F-75015 \\ France; ${ }^{2}$ Department of Pathology, School of Veterinary \\ Medicine Hannover, Hannover, Germany
}

Cystic fibrosis $(\mathrm{CF})$ is a frequent autosomal recessive disorder caused by mutation of a gene encoding a multifunctionnal transmembrane protein located in the apical membrane of epithelial cells lining exocrine glands, the CF Transmembrane conductance Regulator (CFTR). In an attempt to get a more complete picture of the pleiotropic effects of the CFTR defect on epithelial cells and particularly on the membrane compartment, a bi-dimensional BN/SDS PAGE-based proteomic approach was used on colonic crypts samples from control and CFTR-knockout mice ( $\left.c f t r^{--}\right)$. This approach overcomes the difficulties of membrane protein analysis by conventional 2-D PAGE and is able to resolve multiprotein complexes. Used here for the first time on crude membrane proteins that were extracted from murine colonic crypts, BN/SDS PAGE allows effective separation of protein species and complexes of various origins, including mitochondria, plasma membrane, and intracellular compartments. The major statistically significant difference in protein maps obtained with samples from control and $\mathrm{ctr}^{-/-}$mice was unambiguously identified as mClCA3, a member of a family of calcium-activated chloride channels (CaCCs), considered as key molecules in mucus secretion by goblet cells. On the basis of this finding, we evaluated the overall expression and localization of mClCA3 in the colonic epithelium and in the lung of mice by immunoblot analysis and immunohistochemistry. We found that mClCA3 expression was significantly decreased in the colon and lung of the $c f t r^{-1-}$ mice. In an ex-vivo assay, we show that the $\mathrm{Ca}^{2+}$-dependent (carbachol-stimulated) glycoprotein secretion strongly inhibited by the CaCCs blocker, niflumic acid $(100 \mu \mathrm{M})$, is impaired in the distal colon of $\mathrm{cftr}^{-/-}$mice. These results support the conclusion that a ClCA-related function in the CF colon depends on CFTR expression and may be correlated with the impaired expression of mClCA3.

\section{0 \\ Prevention of Glomerulosclerosis in Obese Diabetic Mice during ACE Inhibition: Role of B2-KININ Receptor}

\author{
M. Buleon, J.-P. Girolami, I. Tack \\ INSERM U388 and Physiology Department, CHU \\ Rangueil, Toulouse Cedex, France
}

Today, angiotensin converting enzyme inhibitors (ACEI) remain the only proven renoprotective treatment against diabetic nephropathy, but their mechanism of action is still debated. This study investigated the effects of a chronic treatment with an ACEI (ramipril), alone or combined with HOE140 (a non peptidic antagonist for the B2kinin receptor), on glomerular filtration rate (GFR, assessed by inulin clearance) and on the development of glomerulosclerosis (GS, analysed by histomorphometry). Glomerular protein expression of signalling pathways was studied by Western Blot: IGF-1 receptor, MAP-kinases ERK1/2, TGF-beta1-receptor II (TGF- $\beta$ RII), RAGE (the receptor for Advanced Glycation End-products), lipid peroxidation (i.e. accumulation of 4-HNE adducts). Experiments were performed using 7-weeks old obese diabetic (C57BLKs db/db) mice that were randomly assigned for 20 weeks to 3 groups: (1) untreated; (2) treated with ACEI alone; (3) treated with ACEI + HOE140.

The development of diabetic GS in $\mathrm{db} / \mathrm{db}$ mice, (superproportional increase in mesangium), was largely prevented by ACEI treatment. Despite such a beneficial effect, the decrease in GFR observed in untreated diabetic mice was worsened by ACEI treatment. This decrease in GFR during ACEI was kinin-dependent as it was reversed by the B2-kinin receptor antagonist. Glomerular expression of TGF- $\beta$ RII, IGF-1R, RAGE, lipid peroxidation, and ERK1/2 activation increased significantly in untreated diabetic mice. ACEI treatment prevents to a various extent the up regulation of TGF-ßRII, IGF1-R, ERK1/2 activation as well as lipid peroxidation. These effects as well as the prevention of GS were abolished by cotreatment with the B2-receptor antagonist.

The main findings are: (1) the prevention of GS is independent of the haemodymanic effects of ACEI; (2) ACEI treatment is associated with the inhibition of TGF- $\beta$ RII, IGF-1R and RAGE upregulation and lipid peroxidation; (3) activation of the B2-kinin receptor plays a critical role in the nephrotective effects of ACEI.

\section{1}

\section{Role of the 2nd Extracellular Loop of Na,K-ATPase a Subunit in the Control of the Acessibility of K1 lons to Their Binding Sites}

\section{O. Capendeguy, J.-D. Horisberger}

Department of Pharmacology and Toxicology, Lausanne, Switzerland

The structural model of Na,K-ATPase established by homology with calcium-ATPase (SERCA), as well as mutation studies, has shown the importance of transmembrane helices M4, M5 and M6 in the $\mathrm{Na}^{+}$and $\mathrm{K}^{+}$binding sites. In order to understand the control of the accessibility of extracellular $\mathrm{K}^{+}$ions to their binding sites, we studied the role the 2nd extracellular loop that connects helices M3 and M4, a region that has little sequence homology with SERCA. Thirteen cysteine mutants (E314C to G326C) were generated and studied by electrophysiology (two-electrode voltage clamp) following expression in Xenopus oocytes. We investigated the accessibility of these positions by observing the effects of a membrane impermeant methane-thio-sulfonate sulfhydryl reagent MTSET. In addition, the effects of MTSET binding on the voltage-dependent activation by external $\mathrm{K}^{+}$were studied for selected reactive mutants. Four mutants were strongly modified by MTSET: Y315C, W317C and I322C were inhibited, whereas E314C was stimulated. The apparent affinity for extracellular $\mathrm{K}^{+}$was strongly increased by MTSET binding in the W317C and the $\mathrm{I} 322 \mathrm{C}$ mutants. In the E314C mutant, the modifications due to the mutation itself (reduction in $\mathrm{V}_{\max }$, increase in apparent 
affinity in $\mathrm{K}^{+}$) were corrected by MTSET binding. For the W317C and I322C mutants, MTSET induced a shift of the charge/potential relationship towards positive potentials, indicating an increase in affinity for external $\mathrm{Na}^{+}$.

These results, combined with those previously published about the 3rd extracellular loop (Capendeguy and Horisberger $J$ Physiol 2005;565:207-218), show a complementary function of these 2 loops in the control of the accessibility of the extracellular cations to their binding sites.

Supported by the Swiss National Science Foundation grant \# 31-65441.01 to J-D. H.

12

\section{Genetic Ablation of the Ammonia Transporter Rhbg in Mouse Does Not Impair Renal Ammonium Excretion}

R. Chambrey 1 , D. Goossens ${ }^{2}$, S. Bourgeois ${ }^{1}$, N. Picard ${ }^{1}$ M. Bloch-Faure ${ }^{3}$, F. Leviel1,4, V. Geoffroy ${ }^{5}$, M. Cambillaud ${ }^{6}$, Y. Colin ${ }^{2}$ M. Paillard ${ }^{1,4}$, P. Houillier ${ }^{1,4}$, J.P. Cartron²,

D. Eladari ${ }^{1,7}$

${ }^{1}$ INSERM U652, IFR58, Institut des Cordeliers, Université René Descartes, ${ }^{2}$ INSERM U665, Institut National de la Transfusion Sanguine, ${ }^{3}$ UMR 7134 CNRS-Université Pierre et Marie Curie, ${ }^{4}$ Département de Physiologie, Hôpital Européen Georges Pompidou, AP-HP, ${ }^{5}$ INSERM U439, Hôpital Lariboisière, ${ }^{6}$ Service de Biochimie, Hôpital Européen Georges Pompidou, AP-HP, ${ }^{7}$ Département de Physiologie, Hôpital Necker-Enfant Malades, AP-HP, Paris, France

Ammonium transport by the distal nephron and ammonium detoxification by the liver, are critical for achieving regulation of acid-base balance and to avoid hyperammonemic hepatic encephalopathy, respectively. Therefore, it has been proposed that $\mathrm{Rhbg}$, a member of the Mep/Amt/Rh ammonia channel superfamily may be involved in some forms of distal tubular acidosis and congenital hyperammonemia. We have tested this hypothesis by inactivating $R H b g$ gene in mouse by insertional mutagenesis. Histochemical studies analyses confirmed that $R H b g \mathrm{KO}$ mice did not express Rhbg protein. Under basal conditions, the KO mice did not exhibit encephalopathy and survived well. They did not exhibit hallmarks of distal tubular acidosis since neither acid-base status, plasma potassium concenration, nor bone mineral density were altered by $R H b g$ disruption. They did not have hyperammonemia or disturbed hepatic ammonia metabolism. Moreover, the KO mice adapted to a chronic acid-loading challenge by increasing urinary ammonium excretion as well as their wild type controls. Finally, $\mathrm{NH}_{3}$ permeability of the cortical collecting duct measured by in vitro microperfusion of collecting duct from KO and wild type mice was identical with no apparent effect of the absence of Rhbg protein. We conclude that Rhbg is not a critical determinant of ammonia transport in vivo.
13

\section{Vasopressin-Stimulated CFTR $\mathrm{CI}^{-}$Currents Are Increased in the Renal Collecting Duct Cells of a Mouse Model of Liddle's Syndrome*}

C.T. Chang ${ }^{1}$, M. Bens ${ }^{1}$, E. Hummler ${ }^{3}$, S. Boulkroun ${ }^{1}$, L. Schild ${ }^{3}$, J. Teulon' ${ }^{2}$ B.C. Rossier ${ }^{3}$, A. Vandewalle ${ }^{1}$

${ }^{1}$ INSERM U478, Faculté de Médecine Xavier Bichat; ${ }^{2}$ CNRS-FRE 2468, Institut des Cordeliers, Paris, France; ${ }^{3}$ Institut de Pharmacologie et de Toxicologie, Université de Lausanne, Lausanne, Switzerland

Liddle's syndrome is a genetic form of hypertension linked to $\mathrm{Na}^{+}$ retention caused by activating mutations in the $\mathrm{COOH}$ terminus of the $\beta$ or $\gamma$ subunit of the epithelial sodium channel $(\mathrm{ENaC})$. In this study, we used the short-circuit current $\left(I_{s c}\right)$ method to investigate the effects of deamino-8-D-arginine vasopressin (dDAVP) on $\mathrm{Na}^{+}$and $\mathrm{Cl}^{-}$fluxes in primary cultures of cortical collecting ducts (CCDs) microdissected from the kidneys of mice with Liddle's syndrome carrying a stop codon mutation, corresponding to the $b$-ENaC $\mathrm{R}_{566}$ stop mutation (L) found in the original pedigree. Compared to wild-type $(+/+)$ CCD cells, untreated $\mathrm{L} /+$ and $\mathrm{L} / \mathrm{L}$ CCD cells exhibited 2.7- and 4.2-fold increases, respectively, in amiloride-sensitive $(\mathrm{Ams}) \mathrm{I}_{s c}$, reflecting $\mathrm{ENaC}$ dependent $\mathrm{Na}^{+}$absorption. Short-term incubation with dDAVP caused a rapid and significant increase ( $\sim 2$-fold) in $\mathrm{Ams}_{s c}$ in $+/+$, but not in $\mathrm{L} /+$ or L/L CCD cells. In sharp contrast, dDAVP induced a greater increase in 5-nitro-2-(3-phenylpropamino)benzoate (NPPB)-inhibited apical $\mathrm{Cl}^{-}$currents in amiloride-treated $\mathrm{L} / \mathrm{L}$ and $\mathrm{L} /+$ cells than in their $+/+$ counterparts. $I_{s c}$ recordings performed under apical ion substituted conditions revealed that the dDAVP-stimulated apical secretion of $\mathrm{Cl}^{-}$, which was absent in cultured CCDs lacking CFTR, was 1.8-fold greater in $\mathrm{L} /+$ and 3.7-fold greater in $\mathrm{L} / \mathrm{L}$ CCD cells than in their $+/+$ CCD counterparts. After the basal membrane had been permeabilized with nystatin and a basal-to-apical $\mathrm{Cl}^{-}$gradient had been imposed, dDAVP also stimulated larger $\mathrm{Cl}^{-}$currents across $\mathrm{L} / \mathrm{L}$ and $\mathrm{L} /+\mathrm{CCD}$ layers than $+/+$ CCD layers. These findings demonstrate that vasopressin stimulates greater apical CFTR $\mathrm{Cl}^{-}$conductance in the renal CCD cells of mice with Liddle's syndrome than in wild-type mice. This effect could contribute to the enhanced $\mathrm{NaCl}$ reabsorption observed in the distal nephron of patients with Liddle's syndrome.

*J Physiol (London), 2005;562:271-284. 


\section{4 \\ HB-EGF is Necessary to Calcium Influx and Vasoconstriction Induced by Endothelin-1}

\author{
D. Chansel ${ }^{1}$, S. Vandermeersch ${ }^{1}$, M. Ciroldi ${ }^{1}$, \\ L.F. Jackson', A.-M. Gomez , D.C. Lee ${ }^{3}$, T.M. Coffman", \\ S. Richard ${ }^{3}$, J.-C. Dussaule ${ }^{1,5}$, P.-L. Tharaux ${ }^{1}$ \\ ${ }^{1}$ INSERM U702, Hôpital Tenon, ${ }^{2}$ Lineberger Comprehensive \\ Cancer Center, UNC School of Medicine, Chapel Hill, \\ 3INSERM U637, CHU Arnaud de Villeneuve, 34295 \\ Montpellier Cedex 05, ${ }^{4}$ Duke University Medical Center, \\ Durham, ${ }^{5}$ Université Pierre et Marie Curie and School of \\ Medicine Saint-Antoine, Paris, France
}

Epidermal growth factor receptor (EGFR) transactivation is a mediator of endothelin-1 (ET-1) signaling in cultured vascular smooth muscle cells (VSMCs) and isolated arteries. EGFR was shown to be required for full ET-1-induced constrictive response. The present study used isolated mouse arteries and mouse and human vascular smooth muscle cells to investigate the mechanisms of EGFR transactivation and its ligand heparin-binding EGF (HB-EGF), under ET-1-induced calcium signaling and vascular tone. Baseline blood pressure was similar in HB-EGF - / - and HB-EGF + / + male mice. However HB-EGF-/mice were insensitive to the vasopressive action of infused ET-1. ET-1 addition resulted in weaker isovolumetric tone development in HB-EGF deficient vessels, an effect mimicked by EGFR inhibition and phosphoinositide 3-kinase (PI3K) inhibition. Next, cultured VSMCs from normal and from littermate waved-2 (wa2) mice were exposed to ET-1. Wa2 cells display a genetically determined partial loss of function of EGFR tyrosine kinase activity. Wa2 phenotype was associated with a $50 \%$ decrease in ET-1 induced calcium peak, an effect reproduced with preincubation of wild type VSMCs with EGFR inhibitor AG1478 and PI3K inhibitors LY29002 and wortmannin. Mutated DT toxin (CRM197) is able to neutralize HB-EGF binding to EGFR. Pre-treatment of human VSMCs from internal mammary arteries with CRM197 significantly blunted ET-1-stimulated calcium transients.

These findings suggest that the mechanism of ET-1-induced vasoconstriction involves HB-EGF-mediated EGFR transactivation. The mechanism of this functional cascade requires modulation of agonistinduced calcium transient by EGFR and PI3K with extremely fast kinetics.

\section{5}

Renal Epithelial Collecting Duct Intercalated Cells Play Key Roles in Recognition and Innate Resistance to Uropathogenic Escherichia Coli Causing Pyelonephritis

\author{
C. Chassin', J.-M. Goujon², S. Darche ${ }^{3}$, F. Cluzeaud1, \\ M. Bens ${ }^{1}$, L. du Merle ${ }^{4}$, C. Le Bouguénec ${ }^{4}$, \\ D. Buzoni-Gate/ ${ }^{3}$, A. Vandewalle 1 \\ ${ }^{1}$ INSERM U478, Faculté de Médecine Xavier Bichat، \\ ${ }^{2}$ Service d'Histologie et de Cytologie, ${ }^{2} \mathrm{CHU}$, Poitiers, \\ ${ }^{3} \mathrm{RPPI}$ et ${ }^{4} \mathrm{UPBM}$, Institut Pasteur, Paris, France
}

Uropathogenic Escherichia coli (E. coli) (UPEC) are responsible for the majority of urinary tract infections (UTIs). However, the participation of renal tubule cells in early innate immune response and renal bacterial invasion still remains poorly defined. Here we analyzed the profile of response of pro-inflammatory mediators in kidneys of adult female CBA mice infected by transurethral inoculation $\left(10^{8}\right.$ bactéria/50 $\left.\mu l\right)$ with uropathogenic E. coliAL10 and $E$. coliAL511 isolates harbouring the same set of virulent factors and with E. coliMG1655 (K12) devoid of pathogenicity. Significant greater amounts of E. coliAL10 and E. coliAL511 than E. coliMG1655 were detected in bladder and kidneys of CBA mice $48 \mathrm{~h}$ after bacterial inoculation. Infected kidneys exhibited important infiltrates of leucocytes in the medulla and papilla and increased levels of pro-inflammatory mediator mRNA expression (mainly IL-1 $\beta$, IL-6 and MIP-2, the murine functional equivalent of IL-8) when compared to that measured in kidneys from naive mice or mice infected with E. coliMG1655. The expression of the Toll-like receptor (TLR) 4, which recognizes the lipopolysaccharide (LPS) of gram-negative bacteria, but not of TLR2, also significantly increased in kidneys from mice infected with UPEC. Immunohistochemical studies revealed preferential adhesion (AL10) and/or invasion (AL511) of UPEC to collecting duct (CD) intercalated cells. A greater amount of E. coliAL511 was also recovered in CD of kidneys from day-2 postinfected $\mathrm{C} 3 \mathrm{H} / \mathrm{HeJ}$ carrying a non-functional TLR4 $\left(8 \times 10^{5} / \mathrm{kidney}\right.$, $\mathrm{n}=9)$ than their TLR4-expressing $\mathrm{C} 3 \mathrm{H} / \mathrm{HeOuJ}$ mice $\left(7.5 \times 10^{3} / \mathrm{kid}-\right.$ ney, $\mathrm{n}=6)$ counterparts. Moreover, apical addition of E. coliAL511 $\left(5 \times 10^{5}\right.$ bacteria, $\left.3 \mathrm{~h}\right)$ to confluent cultures of medullary CD dissected from the kidneys of $\mathrm{C} 3 \mathrm{H} / \mathrm{HeOuJ}$ mice and grown of permeable filters, induced dramatic increased in MIP-2, TNF- $\alpha$, and to a lesser extent iNOS and RANTES mRNAs expressions, preferential apical secretion of the MIP-2 protein, and apical-to-basal translocation of UPEC without alteration of the tight junction permeability. These findings provide lines of strong evidence that renal tubule epithelial collecting duct cells actively participate to the initiation of innate immune response for the host defence against UPEC through a TLR4dependent pathway and that intercalated cells may represent a site of entry for invading pyelonephritogenic $E$. coli strains. 
16

\section{Involvement of Hyaluronan and CD44 in Tubular Regeneration after Acute Renal Ischemia/Reperfusion Injury in the Rat}

\author{
A.E. Declèves ${ }^{1}$, N. Caron², G. Toubeau² ${ }^{2}$ D. Nonclercq ${ }^{2}$, \\ A. Legrand ${ }^{2}$, B. Flamion ${ }^{1}$ \\ FUNDP, 61 rue de Bruxelles Namur, ${ }^{1} \mathrm{UMH}$, Belgium
}

Renal ischemia/reperfusion (I/R) injury involves hemodynamic and cellular dysfunctions, and renal inflammation. Recovery of renal function after I/R occurs via cell proliferation and/or migration throughout the kidney. CD44, the major hyaluronan (HA) receptor, is considered as an adhesion molecule, as well as a proven factor for cell motility and differentiation. It can mediate inflammatory cell function and tumor growth. Since after I/R, HA has been shown to accumulate in the renal cortex $(\mathrm{C})$ and CD44 is upregulated, they could be involved in renal post-ischemic regeneration. To address this point, the localization and expression of HA, CD44, vimentin, and PCNA-positive cells were characterized by immunohistochemistry at different time-points after $\mathrm{I} / \mathrm{R}$ in uninephrectomized rats in $\mathrm{C}$, outer and inner stripes of outer medulla (OS, IS) and inner medulla (IM). In controls, HA was localized to the interstitium of IM and IS, and CD44 was mainly present on basolateral membranes of collecting ducts in IS. After I/R, HA and CD44 staining appeared in C and OS as soon as $12 \mathrm{~h}$ after I/R and progressively increased until day 7 , whilst proliferation in tubules and the interstitium was detected mainly from $24 \mathrm{~h}$ to day 7 . At this stage, the highest density of HA was around regenerating tubules. CD44 was strongly expressed in the membranes of regenerating tubules, where it extended onto the apical surface. CD44 was also detected on some interstitial cells. As observed by double-labelled immunofluorescence, CD44 and vimentin were co-expressed in undifferentiated cells involved in tubular re-epithelialisation. At day 15 , proliferation was almost back to control levels while CD44 expression was decreased and restrained to 'remodelling' areas. In conclusion, the increased expression of HA and CD44 after I/R was temporally and locally associated with intense tubular proliferation, as assessed by dedifferentiation markers, and with cell motility assessed by vimentin. HA and CD44 are potentially important factors in recovery from post-ischaemic acute renal failure, since recovery of renal function is dependent on re-epithelialisation.

17

\section{Intrinsic Gluconeogenesis Is Enhanced in Renal Proximal Tubules of Zucker Diabetic Fatty Rats}

\author{
A. Eid, S. Bodin, B. Ferrier, H. Delage, M. Boghossian, \\ M. Martin, G. Baverel, A. Conjard
}

Laboratoire de Physiopathologie Métabolique et Rénale, INSERM UMR 499, Faculté de Médecine RTH Laennec, Université Claude-Bernard-Lyon1, Lyon, France

Recent studies indicate that renal gluconeogenesis is substantially stimulated in type 2 diabetic patients, but the mechanism responsible for such stimulation remains unknown. Therefore, in the present study, we have tested the hypothesis that renal gluconeogenesis is spontaneously elevated in the Zucker Diabetic Fatty rat which is considered to be an excellent model of type 2 diabetes. For this study, isolated renal proximal tubules from diabetic rats and from their lean non-diabetic littermates were incubated in the presence of physiological gluconeogenic precursors. The marked stimulation of gluconeogenesis observed from near-physiological concentrations of lactate $(+38 \%)$, glutamine $(+51 \%)$ and glycerol $(+66 \%)$, that occurred despite a reduced cellular ATP level, was not due to an increase in substrate removal but rather was associated with an increase in the activities and mRNAs levels of the key gluconeogenic enzymes involved, i.e. mainly of phosphoenolpyruvate carboxykinase and, to a lesser extent, of glucose-6phosphatase and fructose-1,6-bisphosphatase. Experimental evidence suggests that glucocorticoids and cAMP were two factors responsible for the long-term and probably multifactorial stimulation of renal gluconeogenesis observed in the diabetic rats. These data, together with the increased renal mass $(+38 \%)$ observed, lend support to the view so far based only on in vivo studies performed in humans that renal gluconeogenesis may be stimulated and crucially contribute to the hyperglycaemia of type 2 diabetes.

18

\section{Hyperaldosteronemia and Activation of ENaC Are Not Required for Sodium Retention in Puromycin-Induced Nephrosis}

G. Favre, S. Lourdel, J. Loffing, M. Paulais, A. Nissant,

J. Teulon, A. Doucet, G. Deschênes

CNRS/UPMC 7134, IFR 58, Institut des Cordeliers, 75270

Paris CD 06, France

Oedema and ascites in nephrotic syndrome mainly result from increased $\mathrm{Na}^{+}$reabsorption along connecting tubules and cortical collecting ducts (CCD). In puromycin aminonucleoside (PAN)-induced nephrosis, increased $\mathrm{Na}^{+}$reabsorption results from increased activity of $\mathrm{ENaC}$ and $\mathrm{Na}^{+}, \mathrm{K}^{+}$-ATPase, two targets of aldosterone. Because plasma aldosterone increases in PAN-nephrotic rats, we investigated the aldosterone dependency of ENaC activation in PAN nephrosis.

For this purpose, (a) we compared the mechanism of ENaC activation in nephrotic and sodium-depleted rats, and (b) we evaluated $\mathrm{ENaC}$ activity in PAN nephrotic rats in the absence of hyperaldosteronemia.

The mechanism of ENaC activation was similar in CCDs from nephrotic and sodium depleted rats, as demonstrated by (a) increased number of active ENaC evaluated by patch clamp, (b) increased levels of apical $\mathrm{ENaC}$ subunits determined by immunohistochemistry, (c) shift in the electrophoretical profile of $\gamma \mathrm{ENaC}$ subunit, and (d) increased abundance of $\beta$ ENaC mRNAs.

Corticosteroid-clamp fully prevented all PAN-induced changes in $\mathrm{ENaC}$. Altogether, these results demonstrate that hyperaldosteronaemia accounts for ENaC activation in PAN nephrosis. However, in response to PAN, corticosteroid-clamped rats developed a full-blown nephrotic syndrome with massive albuminuria, sodium retention and ascites. In corticosteroid-clamped rats, sodium retention was associated with induction of $\mathrm{CCD} \mathrm{Na}{ }^{+}, \mathrm{K}^{+}$-ATPase and was reversed by treatment with low doses of amiloride.

We conclude that in PAN nephrosis: (a) ENaC activation in CCD is dependent on hyperaldosteronaemia, (b) sodium retention and induction 
of $\mathrm{Na}^{+}, \mathrm{K}^{+}$-ATPase in CCD are independent of hyperaldosteronaemia, and (c) $\mathrm{ENaC}$ is not limiting for sodium reabsorption in the distal nephron.

\section{9}

\section{Discoidin Domain Receptor 1 Null Mice Are Protected Against the Hypertension-Induced Renal Vascular and Glomerular Disease}

\author{
M. Flamant, S. Placier, C. Curat, J.C. Dussaule, \\ C. Chatziantoniou \\ INSERM U702, Hôpital Tenon, Paris, France
}

Discoidin domain receptor 1 (DDR1) is a nonintegrin collagen receptor that displays tyrosine-kinase-MAPK activity. It is constitutively expressed in a variety of cells including smooth muscle and mesangial cells, and is inducible in leukocytes. The objective of the present study was to investigate the involvement of DDR1 activation in the development of renal vascular fibrosis.

To this end, the angiotensin - induced hypertensive model was applied in genetically deficient to DDR1 mice and in wild type controls. After 4 weeks of angiotensin II treatment $(1 \mu \mathrm{g} / \mathrm{kg} / \mathrm{min}$ through subcutaneous osmotic pumps combined to high salt fed), wild type mice developed hypertension $(148 \pm 9 \mathrm{mmHg})$ associated with glomerular sclerosis and perivascular leucocyte infiltration. Systolic pressure was similar $(147 \pm 11 \mathrm{mmHg})$ in the DDR1 deficient mice, but the histological lesions of glomerular fibrosis and inflammation were significantly blunted (sclerotic glomeruli: $5 \pm 3 \%$ vs. $22 \pm 8 \%$, p $<0.05$; score of cellular infiltrate: $2.5 \pm 0.3$ vs. $0.4 \pm 0.3, p<0.01$ ). Similar results were obtained in mice treated with a NO synthase inhibitor (L-NAME) for 20 weeks (another model of hypertension). Immunostaining for collagen I, CD3 and F4-80 was important in the renal cortex of hypertensive wild type animals, but negligible in DDR1 deficient mice. In addition, spleens became hypertrophic during hypertension in wild type, but not in DDR1 deficient mice $(240 \pm 15$ vs. $175 \pm 12 \mathrm{mg}, \mathrm{p}<0.01)$.

In parallel experiments, acute injections of LPS induced a significantly lower rate of mortality in DDR $1(10 \% \mathrm{vs} .60 \%$ mortality for $10 \mu \mathrm{g}$ of LPS at 24h); MCP-1 secretion markedly increased in a LPS-dosedependent manner in renal cortical slices from wild type animals, whereas it remained unchanged and at low values in DDR deficient mice.

In conclusion, DDR1 plays a major role in the inflammatory process leading to the development of vascular and glomerular fibrosis associated to hypertension and it could provide a novel therapeutic target to treat these pathologies.

\section{0}

Externalized Calpains are Involved in Tubular Repair after Ischemic Acute Renal Failure

C. Frangié, W. Zhang, J. Perez, Y.-C.X. Dubois, J.-P. Haymann, L. Baud

INSERM U702, Hôpital Tenon, 4 rue de la Chine, Paris, France

Calpains are intracellular $\mathrm{Ca}^{2+}$-dependent cysteine proteases. In ischemic acute renal failure, they play a key role in proximal tubule cell injury and death. In turn, cell necrosis is responsible for their release into the extracellular environment, raising the question as to whether externalized calpains are involved in proximal tubule repair.

To assess in vivo the impact of externalized calpains, a bilateral ischemic renal injury was produced in C57BL/6 mice by clamping both renal pedicles for $25 \mathrm{~min}$. The clamp was then removed to allow reperfusion and mice were given IP injection of non-permeant calpain specific inhibitor calpastatin. They were killed after 1, 2, 3, or 4 days of reperfusion. We found at day 1 and 2 a statistically higher increase in serum creatinine $(95.3 \pm 14.6$ vs. $64 \pm 9.1$ and $126.3 \pm 28.5$ vs. $65 \pm 10.5 \mu \mathrm{M}$, respectively; $\mathrm{p}<0.05)$ and blood urea nitrogen $(42.5 \pm 5.8$ vs. $29.5 \pm 3.9$ and $71 \pm 11.2$ vs. $35.5 \pm 6.6 \mathrm{mM}$, respectively; $\mathrm{p}<0.05$ ) in calpastatin-treated mice as compared to controls. This worsening of renal dysfunction was associated with a significant increase in tubular injury, especially in the outer medulla.

To identify the molecular mechanisms whereby externalized calpains would exert a protective effect, in vitro experiments were performed using a human renal tubular cell line (HK-2). Exposure of these cells to $0.16-0.64 \mathrm{mU} / \mathrm{ml}$ of $\mu$-calpain for $1 \mathrm{~h}$ did not affect their viability and proliferation, but decreased their adhesion to extracellular matrix and, hence, increased their mobility. These changes were explained by the calpain-dependent cleavage of fibronectin in extracellular matrix, the disengagement of $\alpha \mathrm{V} \beta 3$ integrin, the activation of protein kinase $\mathrm{A}$, and the redistribution of integrin-cytoskeleton linkages.

In conclusion, these studies provide the first evidence that, after ischemic acute renal failure, calpain release may enhance the mobility of surviving tubular cells, thus favouring tubular repair.

\section{1 \\ Characterisation of New Mutations of Human Renal Phosphate Co-Transporter NPT2a \\ L. Galmiche, N. Bakouh, G. Planelles, B. Grandchamp, \\ A. Edelman, G. Friedlander, D. Prié \\ INSERM U426 and U467, Hôpital Necker, Hôpital Bichat, Paris, France}

The sodium-phosphate co-transporter NPT2a plays a major role in renal phosphate $(\mathrm{Pi})$ reabsorption. Recently, two human heterozygous mutations of NPT2a were identified in patients presenting with bone demineralisation or nephrolithiasis. Mutant NPT2a were expressed in oocytes, showing decreased Pi-induced inward current and a dominant negative effect (Prié et al., New Engl J Med, 2002). Two new mutations of NPT2a have been identified (P75S and A133V). Patients are heterozygous for these mutations and have nephrolithiasis and hyperphosphaturia. We functionally characterised mutant NPT2a by injecting $10 \mathrm{ng}$ of wild type (WT) or mutant NPT2a RNA into Xenopus oocytes. After 48 to $72 \mathrm{~h}$ we measured Pi-induced current (I, nA; [Pi] $=1 \mathrm{mM}$ ) using two-electrode voltage-clamped oocytes $(\mathrm{Vc}=-50 \mathrm{mV})$. Results are expressed as mean \pm SE, $30<\mathrm{n}<60$.

Pi-induced current was significantly decreased in oocytes expressing mutant NPT2a compared to oocytes expressing WT NPT2a (WT: $\mathrm{I}=-43 \pm 15$; P75S: $\mathrm{I}=-3 \pm 2 ; \mathrm{A} 133 \mathrm{~V}: \mathrm{I}=-29 \pm 15 ; \mathrm{p}<0.01)$, showing functional deficiency of mutant NPT2a. Pi-induced current is also decreased in oocytes injected with $10 \mathrm{ng}$ of WT RNA $+10 \mathrm{ng}$ of mutant RNA compared to oocytes injected with 10 ng of WT RNA alone 
(WT: $\mathrm{I}=-43 \pm 15 ; \mathrm{WT}+\mathrm{P} 75 \mathrm{~S}: \quad \mathrm{I}=-26 \pm 9 ; \mathrm{WT}+\mathrm{A} 133 \mathrm{~V}$ : $\mathrm{I}=-29 \pm 15 ; \mathrm{p}<0.01$ ), showing a dominant negative effect.

To conclude, we describe a relationship between electrophysiological dysfunction of mutant NPT2a and patients' hyperphosphaturia. This may be due either to reduced activity or reduced membrane expression of mutant NPT2a. Nevertheless, this study suggests that mutant NPT2a may be involved in some human nephrolithiasis.

\section{2}

\section{Pathophysiological Regulation of NDRG2 in the Colon: Role of Aldosterone and Inflammation}

D. Gonzalez-Nunez, S. Boulkroun, M.A. Ramirez-Gallardo, A. Bado, R. Ducroc, N. Courtois-Coutry, N. Farman

INSERM U478 and U410, Faculté de Médecine Bichat, Paris, France

The distal colon constitutes a classical aldosterone-responsive epithelium. We have recently identified NDRG2 ( $N$-myc Downstream Regulated Gene 2) as a very early stimulated gene by aldosterone, both in the kidney and the colon of rats. NDRG2 belongs to a family of genes of unknown function, which is conserved in plants and animals, suggesting important functions. Its identity with MESK2, a gene recently identified in Drosophila, suggests that it may be involved in the Ras/MAPK signaling pathway. We have worked with colons of adrenalectomized rats to investigate the NDRG2 expression in aldosterone- induced sodium absorption and inflammation. NDRG2 protein was induced $(1 \mathrm{~h})$ by aldosterone (ALDO) injection in vivo (two fold) in distal colon but not in proximal colon. ALDO stimulated ERK phosphorylation (without changes in JNK or p38). Moreover the aldosterone-induced short circuit current in ex vivo experiments was blocked with the MAP kinase inhibitor UO126, suggesting that MAP kinase signaling pathway is important for aldosterone regulation of sodium transport in this epithelia.

It has been recently reported that ALDO could modulate inflammation in several tissues. However there is little information on the signaling pathways that link ALDO and inflammation status. We have analyzed the effect of colonic inflammation on NDRG2 expression. Experimental colitis was induced in rats by treatment with $5 \%$ dextran sodium sulfate (DSS) for 7 days. This treatment produces a severe disruption of the distal colonic epithelium with minor alterations in the proximal colon and a imbalance between the pro and anti inflammatory cytokines levels. We found that NDRG2 mRNA and protein levels were induced in proximal colon of DSS rats. Ex vivo treatment of rat colons with the antinflammatory IL13 reduced NDRG2 proteins levels.

These data demonstrate that the colonic expression of NDRG2 is under the control of both aldosterone and the cytokines and that NDRG2 may represent a new actor in the pro-inflammatory mechanisms of aldosterone.

\section{3}

\section{Identification of Differentially Expressed Genes between Fetal Kidneys from Control and Diabetic Mothers}

\author{
I. Guinobert, M. Viltard, D. Piquemal, N. Freund, \\ M. Lelièvre-Pégorier \\ INSERM U652, Institut Biomédical des Cordeliers, \\ 15 rue de l'Ecole de Médecine, 75270 Paris Cedex 06, France
}

During the last past decade, our laboratory demonstrated that modifications of foetal environment cause a nephron deficit, which in turn may have consequences in later life for diseases. Particularly, we have recently demonstrated that in utero exposure to maternal diabetes impairs renal development.

In order to unravel the genetic basis of renal organogenesis and its alteration, we used the SADE method that allows large-scale quantitative gene expression measurements in biological samples.

We first established an embryonic kidney library from 14 days post coitum control foetuses. 7689 tags were sequenced and yielded 4507 unique transcripts. Among them, we identified 65\% mRNA sequences with known function, $22 \%$ corresponded to expressed sequenced tags (EST) and $12 \%$ represented unidentified genes. A comparison with already published adult kidney library revealed 472 genes differentially expressed $(\mathrm{p}<0.01)$. Most of these genes were expressed at higher levels or only expressed in the foetal kidney library. Among them, we identified a candidate gene implicated in nephrogenesis: Thymosin beta 4 .

A second library from fetal kidneys of off spring of diabetic mothers (STZ model) has been constructed. 6760 tags were sequenced and yielded 3973 unique transcripts. These transcripts identified 59\% mRNA sequences, $20 \%$ matched with EST and 21\% represented unidentified genes. Comparison between this library and the control one identified 79 differentially expressed tags $(\mathrm{p}<0.05)$. Among these tags we found unknown genes BMP4 and Hexokinase 1, whose expression increased in foetal STZ kidneys, and Thymosin beta 4, which was greatly downregulated in STZ kidneys.

This study allowed us to identify candidate genes implicated in early renal development and investigation of the role of Thymosin beta 4 during impaired renal organogenesis is under study.

\section{4 \\ Identification of a Potential Casein Kinase2 (CK2) Site within the CBS2 Domain Important for CIC-2 Channel Trafficking, Expression and Function}
A. Hinzpeter ${ }^{1}$, J. Lipecka', M. Siwiak², F. Brouillard', P. Zielenkiewicz ${ }^{2}$, J. Fritsch ${ }^{1}$, A. Edelman ${ }^{1}$
'INSERM U467, Université Paris 05, Paris, France;
${ }^{2}$ University of Warsaw, Warsaw, Poland

Expression of the ClC-2 voltage-gated chloride channel in epithelia suggests a role for this channel in transepithelial $\mathrm{Cl}^{-}$transport. Recently, ClC-2 was demonstrated to serve as an exit pathway for $\mathrm{Cl}^{-}$in the basolateral membranes of the colon. On the other hand, localization of 
$\mathrm{ClC}-2$ at the apical membrane of airway cells suggests that $\mathrm{ClC}-2$ could represent an alternative pathway for impaired $\mathrm{Cl}^{-}$transport in $\mathrm{CF}$. At the molecular level, $\mathrm{ClC}$ channels possess a long cytosolic $\mathrm{C}$-terminus containing 2 CBS domains. These domains have been suggested to play a role in channel trafficking and function. In this context, we studied the relevance of a threonine residue (T840) located within a consensus CK2 site in the CBS2 domain of ClC-2. Mutations T840V and T840E were obtained by site-directed mutagenesis. Coding sequences were subcloned in pIRES-EGFP and stably expressed in HEK293 cells. This model was used to study ClC-2 phosphorylation, expression and localization. Channel function was measured using the patch-clamp technic. The results showed that WTClC-2 could be phosphorylated in vitro by CK2. WTClC-2 localized at the plasma membrane and in intracellular compartments. Mutation T840V lowered channel expression and induced an intracellular retention of the protein. This mutation also induced a marked decrease of $\mathrm{Cl}^{-}$currents associated with a shift of the voltage-dependence of current activation by $45 \mathrm{mV}$. Introduction of a negative charge (T840E) restored all WT characteristics. Inhibition of CK2 decreased WTClC-2 expression. These results demonstrate a key role for a negative charge on residue 840 in agreement with CK2 phosphorylation of this residue for $\mathrm{ClC}-2$ stability, traffic and function.

\section{5 \\ Effect of Intracellular Acidification on K1 Secretion in a Novel CCD Mouse Cell Line}

\section{J.D. Horisberger, E. Gonzalez-Rodriguez, H.P. Gaeggeler, B. Guisan, B.C. Dossier}

Département de Pharmacologie et de Toxicologie, Lausanne, Switzerland

Potassium homeostasis is maintained thanks to the ability of the kidney to regulate urinary excretion of $\mathrm{K}^{+}$, the cortical collecting duct (CCD) being the main site of renal $\mathrm{K}^{+}$secretion. Several factors are known to influence $\mathrm{K}^{+}$secretion: distal $\mathrm{Na}^{+}$delivery, mineralocorticoid hormones, plasma $\mathrm{K}^{+}$concentration and $\mathrm{pH}$, but the mechanism of these regulations is still poorly understood. We took advantage of a recently established mouse cortical collecting duct cell line $\left(\mathrm{mCCD}_{\mathrm{cl} 1}\right)$ (Gaeggeler et al., J Am Soc Nephrol 2005;16:878-891) to investigate the regulation of $\mathrm{K}^{+}$secretion by intracellular $\mathrm{pH}$. $\mathrm{mCCD}_{\mathrm{cl} 1}$ cells were grown on filters and studied under short circuit conditions. After inhibiting the apical $\mathrm{Na}^{+}$conductance with $10 \mu \mathrm{M}$ amiloride, the effects of $2 \mathrm{mM} \mathrm{BaCl}_{2}$ (apical) on the short circuit current $\left(\Delta_{\mathrm{Isc}} \mathrm{Ba}\right)$ were measured while the intracellular $\mathrm{pH}$ was modified through basolateral exposure to solutions with various $\mathrm{pCO}_{2}$ but a similar $\mathrm{pH}$ of 7.4: a high $\mathrm{pCO}_{2}$ solution bubbled with $20 \% \mathrm{pCO}_{2}$ and containing $90 \mathrm{mM}$ $\mathrm{NaHCO}_{3}$ and a low $\mathrm{pCO}_{2}$, nominally $\mathrm{NaHCO}_{3}$ free, HEPES buffered solution bubbled with air. $\Delta_{\text {Isc }} \mathrm{Ba}$ was $10.5 \pm 0.5 \mu \mathrm{A}$ in the low $\mathrm{pCO}_{2}$ conditions and $5.8 \pm 0.4 \mu \mathrm{A}$ in the high $\mathrm{pCO}_{2}$ conditions $(\mathrm{n}=16$ paired measurements, $\mathrm{P}>0.001$ ) indicating an inhibitory effect of intracellular acidification on the activity of apical membrane $\mathrm{K}^{+}$channels. These results show that the $\mathrm{mCCD}_{\mathrm{cl} 1}$ cell line shows a robust barium-sensitive $\mathrm{K}^{+}$secretion and that this $\mathrm{K}^{+}$secretion is modulated by intracellular $\mathrm{pH}$ similarly to what is known for the collecting duct in vivo. In addition these data support the hypothesis that this $\mathrm{K}^{+}$secretion is mediated by ROMK (Kir1.1) channels, which are known to be inhibited by intracellular acidification, a hypothesis also supported by the presence of ROMK mRNA in these cells.

\section{6}

\section{Determination of the Effects of Cadmium Intoxication of Pregnant Rats on New Born Renal Function}

\author{
G. Jacquillet ${ }^{1}$, O. Barbier ${ }^{1}$, M.C. Namorado², D. Martin², \\ J.L. Reyes ${ }^{2}$, P. Poujeol', M. Cougnon ${ }^{1}$ \\ 1 UMR CNRS 6548, Université de Nice-Sophia-Antipolis, \\ 06108 Nice Cedex 02, France; ${ }^{2}$ Departamento de \\ Fisiologia y Biofisica, Centro de Investigacion y de \\ Estudios Avanzados del Instituto Politécnico Nacional, \\ Avenida Instituto Politécnico Nacional, Mexico
}

Cadmium is one of the major industrially used heavy metals. Its intensive exploitation represents a risk for the environment and health as it is found in the atmosphere, soil and water through which it can contaminate the food chain. The aim of this study was to determine the impact of the contamination of drinking water with heavy metal on the renal function of new born, exposed during in utero's life.

To do this, female Wistar rats were intoxicated daily by oral administration with drinking water containing cadmium $(500 \mu \mathrm{g} / \mathrm{kg})$ during pregnancy (21 days). The clearance technique was used to determine the impact of the cadmium exposure on renal function of $2,7,14$ and 60 days old rats.

The investigations of new born from intoxicated mothers show the cadmium to be present in kidney and liver indicating that it goes trough the placental barrier. The results demonstrate that the ageing of the animal and hence the maturation of renal function result in an increase in the glomerular filtration and a diminution of the ion fractional excretion of $\mathrm{Na}^{+}, \mathrm{K}^{+}, \mathrm{Mg}^{2+}$ and $\mathrm{Ca}^{2+}$ compatible with the start of urine concentration phenomena.

Although the renal parameters (glomerular filtration, U/P inulin and urinary flow rate) were not significantly affected with cadmium intoxication until 14 days old, it appeared a renal failure appeared at the age of 60 days showed by a dramatical decrease of the glomerular filtration associated with an increase of the excretion of the main cations. In parallel, immunofluorescence studies have shown, on kidney sections of those rats, a disorganisation of the protein claudin-2, which is involved in extracellular junctions.

In conclusion, this study shows that cadmium intoxication during pregnancy can affect the renal function of the new born. These results must be taken into consideration for those women susceptible to contamination by this heavy metal.

\section{7 \\ Role of Type III Carbonic Anhydrase in Proximal Tubule Function: Lessons from Dent's Disease and Clcn5 Knock-Out Mice

\author{
F. Jouret ${ }^{1}$, P. Gailly ${ }^{1}$, J.-P. Cosijns ${ }^{1}$, S.J. Scheinman², \\ E.I. Christensen ${ }^{3}$, M.-C. Gubler, O. Devuyst ${ }^{1}$ \\ ${ }^{1}$ Université catholique de Louvain, Brussels; ${ }^{2}$ State \\ University of New-York, Syracuse; ${ }^{3}$ University of Aarhus, \\ Aarhus, ${ }^{4}$ Hôpital Necker-Enfants Malades, Paris
}

The functional loss of the chloride channel, $\mathrm{ClC}-5$, in patients with Dent's disease or Clcn5 KO mice causes a severe proximal tubule (PT) 
dysfunction, with impaired endocytosis and trafficking defects. The metabolic outcomes of such PT deficiency remain unknown, which prompted us to investigate renal biopsies from a Dent's disease patient (Gly506Glu mutation) and Clcn5 KO mouse kidneys. Real-time RTPCR, immuno-blotting and -staining analyses demonstrated that $\mathrm{ClC}-5$ inactivation was associated with cell proliferation (osteopontin, PCNA) and oxidative stress (type I SOD, thioredoxin) in PT cells. AFLPderived procedure was performed on $\mathrm{Clcn} 5 \mathrm{KO}$ and WT kidneys to isolate candidate genes involved in adaptation mechanisms. Real-time RT-PCR and immunoblotting analyses confirmed that type III carbonic anhydrase (CAIII) was $\sim 4$-fold induced in $\mathrm{Clcn} 5 \mathrm{KO}$ kidney. In normal kidney, CAIII expression was $\sim 5$-fold lower than CAII, and its segmental distribution included only scattered cells along PT. Immunogold labelling for CAIII showed that this isozyme was mostly present in the cytosol and at the brush border of some PT cells. In Clcn 5 KO kidney, the number of CAIII-positive PT cells dramatically increased, although no morphological abnormalities were noticed in these cells. These findings were confirmed in human CLCN5 mutated kidney samples. Since CAIII has been shown to protect cells against oxidative stress in other organs, we used Opossum kidney cells as in vitro model of PT cells, and exposed them to $\mathrm{H}_{2} \mathrm{O}_{2}$ for $2 \mathrm{~h}$ CAIII mRNA was highly induced in treated cells in comparison to controls. In conclusion, we report on CAIII, a novel kidney CA isozyme with a distribution restricted to scattered PT cells. The induction of CAIII expression in Dent's disease and PT cells exposed to $\mathrm{H}_{2} \mathrm{O}_{2}$ suggests that this isozyme is important to protect PT cells from oxidative damage.

\section{8 \\ $\mathrm{K}^{+}$Channels of the Basolateral Membrane of Mouse Cortical Collecting Duct (CCD)}

\section{S. Lachheb, J. Teulon, M. Paulais \\ UPMC-CNRS UMR7134 - 15, rue de l'Ecole de Médecine 75270 Paris Cedex 06, France}

The basolateral membrane of the Cortical Collecting Duct (CCD) principal cells has $\mathrm{K}^{+}$channels whose molecular nature is unknown. We hypothesized that the tetrameric association of the Kir4.1 or Kir4.2 subunits, either alone or in partnership with Kir5.1 subunit, could underlie these $\mathrm{K}^{+}$channels.

Using real-time PCR on microdissected fragments of mouse CCD, only Kir4.1 and Kir5.1 mRNA were detected, and were expressed at comparable levels. Patch-clamp study of the $\mathrm{K}^{+}$channels localized on the basolateral membrane of CCD principal cells revealed the in situ preponderance of a channel with $\mathrm{K}^{+}$selectivity, with a conductance near $50 \mathrm{pS}$, an intermediate type of inward rectification and an open probability (Po) near 0.4 . With the 'inside-out' patch-clamp configuration, channel activity was shown to be increased with the alkalinisation of the intracellular compartment $(\mathrm{pKa}=7.4)$.

The properties of the $50 \mathrm{pS} \mathrm{K}^{+}$channel of CCD basolateral membrane correlate well with those of the channel formed by the heterotetrameric association of Kir4.1 with Kir5.1 subunits when they are expressed in Xenopus oocytes.

\section{9}

\section{PPAR// Protects Mice from Ischemic Acute Renal Failure}

E. Letavernier, J. Perez, E. Joye, D. Heudes, J. Peltier, J.-P. Haymann, B. Fouqueray, A. Bellocq, B. Desvergnes, W. Wahli, L. Baud

Unité INSERM 702, hôpital Tenon, 4 rue de la Chine

Paris, France

Ischemic acute renal failure is a clinical problem still associated with high morbidity and mortality. Progress in its medical management requires a better knowledge of the molecular mechanisms underlying both death and repair of tubular epithelium. Peroxisome proliferatoractivated receptor $\beta / \delta(\operatorname{PPAR} \beta / \delta)$ protects skin epithelium against apoptosis and thereby participates in the skin wound repair process. Thus, we tested whether PPAR $\beta / \delta$ would be similarly involved in the control of tubular epithelium death and/or repair after renal ischemia/reperfusion. We show that $P P A R \beta / \delta^{+/-}$and $P P A R \beta / \delta^{-/-}$mutant mice undergoing renal ischemia/reperfusion injury exhibit much greater kidney dysfunction and injury than wild type counterparts. Conversely, mice given the specific PPAR $\beta / \delta$ ligand L-165041 for 3 days before renal ischemia are completely protected against glomerular and tubular dysfunction, as assessed by measuring serum creatinine and fractional excretion of $\mathrm{Na}^{+}$, respectively. In addition, L-165041 preconditioning significantly reduces tubular necrosis and apoptosis. Based on in vitro studies, PPAR $\beta / \delta$ seems to act by increasing the epithelial cell spreading and activating the anti-apoptotic Akt signalling pathway. These results provide proof that PPAR $\beta / \delta$ is promising pharmacological target for preconditioning strategy in ischemic acute renal failure.

30

\section{Differential Expression of Argininosuccinate Synthetase and Argininosuccinate Lyase Genes in Male and Female Mouse and Rat Kidneys}

\author{
O. Levillain', C. Brasse-Lagnel2, D. Rabier ${ }^{3}$, P. Parvy ${ }^{3}$, \\ J. Becker ${ }^{1}$, J. Techer ${ }^{1}$, H. Wiesinger', A. Husson ${ }^{2}$ \\ ${ }^{1}$ Faculté de Médecine Laennec, U499 INSERM, 69372 \\ Lyon Cedex 08, ${ }^{2}$ Faculté de Médecine-Pharmacie, Rouen, \\ ${ }^{3}$ Laboratoire de Biochimie Médicale B, Hôpital Necker- \\ Enfants malades, Paris Cedex 15, France; \\ ${ }^{4}$ Physiologisch-Chemisches Institut der Universität, \\ Tuebingen, Germany
}

It is established that L-arginine synthesis occurs in the proximal convoluted tubule (PCT) of mammalian kidneys. However, all studies were performed in male kidneys. This study was conducted to analyze the expression of argininosuccinate synthetase (ASS) and argininosuccinate lyase (ASL) genes in mouse and rat kidneys of both genders. The relative abundance of ASS and ASL mRNAs and proteins were quantitated in the different dissected renal zones and the whole kidneys of male and female mice and rats. Amino acids were quantitated in blood and plasma by HPLC. The results indicate that in both species and genders, ASS and ASL genes were highly expressed in the cortex 
(superficial $>$ deep) compared with the outer medulla. ASS protein was detected predominantly at the apical pole of rat PCTs by immunofluorescence. The levels of ASS and ASL proteins were similar in male and female rats. In contrast, the renal expression of ASS and ASL genes was significantly higher in male mice compared with the females. In conclusion, the intense expression of ASS and ASL genes occur in the same nephron segments in male and female mice and rats. In murine kidneys, although the genes encoding L-arginine-synthesizing enzymes were more highly expressed in males than females, the higher levels of blood and plasma L-arginine measured in females might be explained by a concomitant elevated citrullinemia. Sexual dimorphism in the renal metabolism of L-arginine may occur.

\section{1 \\ Role of Task-2 and CFTR in the Regulation of Cell Volume during Apoptosis in Renal Proximal Tubule Cells}

\section{S. L'Hoste, R. Belfodil, M. Tauc, P. Poujeol}

Laboratoire de physiologie cellulaire et moléculaire CNRSUMR 6548, Université de Nice Sophia-Antipolis Parc

Valrose Nice Cedex 02, France

In a previous work, we demonstrated that TASK-2 and CFTR channels were expressed in kidney proximal cells. These channels were involved in the $\mathrm{K}^{+}$and $\mathrm{Cl}^{-}$efflux that occurred during RVD (Regulatory Volume Decrease). The aim of the present study was to determine the role of TASK-2 and CFTR channels in the regulation of the apoptotic volume decrease (AVD) and in apoptosis. For this purpose renal cells were immortalized from primary cultures of proximal convoluted tubules (PCT) from wild-type and TASK-2 or CFTR knock-out mice (KO). Apoptosis was induced by staurosporine (STS, $1 \mu \mathrm{M})$. Cell volume, $\mathrm{Cl}^{-}$and $\mathrm{K}^{+}$conductances and caspase 3 were monitored during the time course of AVD. In PCT from wild type mice AVD and caspase 3 were strongly impaired by $\mathrm{Cl}^{-}$and $\mathrm{K}^{+}$channel blockers. The $\mathrm{Cl}^{-}$and $\mathrm{K}^{+}$conductances, activated during AVD exhibited characteristics of CFTR and TASK-2 currents respectively. In cells from $c f t r-/-$ mice, staurosporine did not induced significant AVD. Moreover in these cells the caspase activation was blocked by $70 \%$. In cells from task2-/- mice AVD and caspase activation were reduced by $60 \%$. Recording $\mathrm{K}^{+}$conductance showed that TASK- $2 \mathrm{~K}^{+}$ currents could be compensated by calcium-activated $\mathrm{K}^{+}$currents probably through BK channels. This result explained the residual AVD measured in these cells.

In conclusion CFTR and TASK-2 channels participate in the AVD in proximal cells. The $\mathrm{Cl}^{-}$channel involved in this process would be a CFTR-like channel whereas the main $\mathrm{K}^{+}$channels involved would be the TASK- $2 \mathrm{~K}^{+}$channel.

\section{2}

\section{Curcumin Changes the Keratin 18 Network and Translocates DF508-CFTR to the Plasma Membrane}

\author{
J. Lipecka1', C. Norez², N. Bensalem¹, M. Baudouin-Legros', \\ F. Becq², G. Planelles ${ }^{1}$, A. Edelman'1, N. Davezac ${ }^{1,3}$ \\ ${ }^{1}$ Université Paris-Descartes, Faculté de médecine, \\ INSERM U467, site Necker, Paris, ${ }^{2}$ Institut de Physiologie \\ et Biologie Cellulaires, UMR 6187 CNRS, Universite de \\ Poitiers, Poitiers Cedex, ${ }^{3}$ Université Paris XI, Faculté de \\ Sciences d'Orsay Orsay Cedex, France
}

Recently published results have shown that oral administration of curcumin to homozygous $\Delta$ F508-CFTR mice leads to the correction of defect in chloride transport across the nasal epithelium. The same study showed that curcumin treatment induces translocation of $\triangle$ F508-CFTR from ER to the plasma membrane (Egan et al., Science 2004). Since then, conflicting results about curcumin effects on $\triangle \mathrm{F} 508$-CFTR traffic and function have been reported. (Dragomir et al., BBRC 2004) have shown a slight CFTR-related increase in $\mathrm{Cl}^{-}$ effluxes activated by intracellular cAMP, whereas (Loo et al., BBRC 2004) could not detect the mature form of $\Delta$ F508-CFTR after curcumin treatment of cells. Altogether, these studies suggest a cell type-dependent effect of curcumin. In this context, the aim of our study was (i) to verify if the action of curcumin is cell-type-dependent and (ii) knowing that changes in keratin 18 (K18) expression may lead to the translocation of $\Delta$ F508-CFTR to the plasma membrane (Davezac et al., Proteomics 2004), to investigate if the action of curcumin modifies the keratin 18 network. Stably $\triangle F 508-C F T R$ transfected HeLa cells and CFPAC (pancreatic-derived) cells expressing low levels of $\Delta$ F508-CFTR (pancreatic-derived cells) were used. Treatment of both cell lines with $50 \mu \mathrm{M}$ of curcumin for 4 and $16 \mathrm{~h}$ translocates $\Delta F 508$-CFTR to the plasma membrane. The functional assay for CFTR performed on CFPAC cells unmasked a cAMPdependent iodide fluxes suggesting that $\triangle$ F508-CFTR is functional. In another series of experiments, we analysed the K18 network after curcumin treatment. Immunocytochemistry experiments showed that the K18 network is disrupted after treatment and western blot analysis indicate that curcumin increases the phosphorylation level of the serine 52, a signature of K18 network reorganization. In conclusion, our results suggest that $\mathrm{K} 18$ might be a target for pharmacotherapy of CF for patients bearing the $\Delta \mathrm{F} 508$ mutation.

33

\section{Regulation of Epithelial Sodium Transport by the Essential Fatty Acid, Eicosapentaenoic Acid (EPA)}

\section{F. Mies, V. Shlyonsky, A. Goolaerts, S. Sariban-Sohraby \\ Laboratoire de Physiologie, Université Libre de Bruxelles, Belgium}

The epithelial sodium channel is found in apical membranes of a variety of epithelial tissues such as renal collecting duct, lung, and distal colon. The appropriate regulation of this channel is essential for 
the maintenance of sodium balance by the kidney, and hence, for the control of arterial blood pressure. In vivo, a number of hormones and other endogenous factors including polyinsatured fatty acids (PUFAs) regulate these channels.

PUFAs have been shown to modulate enzymes, channels and transporters, to interact with lipid bilayers, and to affect various metabolic pathways as well as gene transcription.

We tested the effects of n-3 PUFAs on amiloride-sensitive sodium transport in A6 cells. Eicosapentaenoic acid (EPA, C20:5, n-3) transiently stimulated amiloride-sensitive open-circuit current (INa) from $4.0 \pm 0.3$ to $7.7 \pm 0.3 \mu \mathrm{A} / \mathrm{cm}^{2}$ within $30 \mathrm{~min}(\mathrm{p}<0.001)$. No activation was seen in the presence of $10 \mu \mathrm{M}$ amiloride. Linoleic acid (C18:2, $\omega-6)$, ETYA (C20:4, $\omega-6)$ or DPA (C22:5, $\omega-6)$ had no effect, while DHA (C22:6, $\omega-3)$ activated amiloride-sensitive INa similarly to EPA. In cell-attached patch-clamp experiments, EPA increased open probability $(\mathrm{Po})$ of sodium channels from $0.45 \pm 0.08$ to $0.63 \pm 0.1$ $(\mathrm{p}=0.02$, paired $\mathrm{t}$-test). This increase was not observed in cell-excised patches. Activation of INa by EPA was not related to the generation of prostaglandins or leukotriens but was prevented by H89, a PKA inhibitor. Likewise, PKA activity was increased with EPA. Although non specific stimulation of phosphodiesterase activity by $\mathrm{CoCl}_{2}$ completely prevented the effect of EPA on sodium transport, no accumulation of cAMP or increase in adenylate cyclase activity was measured in presence of EPA. The PKA pathway is thus likely to be involved in the regulation of $\mathrm{ENaC}$ by EPA, possibly via a shift in the set-point for the effect of cAMP. These results indicate that $\omega-3$ fatty acids may represent a new group of regulators of ENaCs.

\section{4}

The Forkhead Transcription Factor Foxk2 is Selectively Expressed in Collecting Ducts and Inhibits the Activity of the Vasopressin Type II Receptor (V2R) Promoter

\section{A. Mustel, D. Ribes, A. Calmont, E. Fischer, M. Lelièvre- Pégorier, P. Houiller, J. Rossert \\ INSERM U652, centre Biomédical des Cordeliers 75270 Paris Cedex 06, France}

Previous studies have suggested that Forkhead transcription factors regulate the activity of the vasopressin type 2 receptor (V2R) promoter in collecting duct cells and play a role in fate determination of this cells (Calmont A et al., Mol Endocrinol 2000;14:1682). RT-PCR experiments performed using RNA obtained from a human collecting duct cell line and degenerated primers that correspond to a conserved sequence within the Forkhead family led to the isolation of a cDNA encoding a new Forkhead protein, expressed in collecting duct cells, that we named FOXK2. Analysis of its sequence revealed the presence of (1) a Forkhead-associated domain (FHA), highly similar to the one of Foxk1/MNF, (2) a DNA binding domain, related to the Forkhead domain of Foxk1, and (3) a consensus nuclear localization signal. Northern Blot analyses showed that foxk2 is expressed at high levels in kidney, at lower levels in brain and not in other organs. Moreover, in situ hybridization experiments revealed that foxk2 is expressed in kidney selectively in collecting duct cells, and that it starts to be expressed at a time corresponding to the terminal differentiation of collecting duct cells. In co-transfection experiments, over-expression of FOXK2 induced a strong inhibition of the activity of the V2R proximal promoter. Co-transfection experiments using cDNAs encoding a truncated protein lacking the DNA binding domain or a chimeric protein harboring a heterologous DNA binding domain, showed that this repressor effect is due to a combination of on-DNA and off-DNA interactions. Other co-transfection experiments using a cDNA encoding a fusion protein containing the FHA domain C-terminal to a heterologous DNA binding domain showed that the FHA domain is not involved in the repressor effects of FOXK2. Interestingly, over-expression of FOXK2 had only slightly inhibitory effects on the activity of the Hoxb7 promoter. While V2R is expressed in differentiated collecting duct cells, Hoxb7 is expressed in collecting duct cells but also in ureteric bud cells.

Taken together, these results suggest that FOXK2 may play a role in regulating the differentiation of collecting duct cells. Knockout mice have been generated to analyze the in vivo role of FOXK2.

\section{5}

\section{Long Term Effects of In Utero Exposure to Maternal Diabetes on Renal Function and Arterial Pressure in Rats}

\author{
T. Nehiri, M. Viltard, I. Guinobert, N. Freund, P. Houillier, \\ $M$. Lelièvre-Pégorier \\ INSERM U652, IFR58, Université R. Descartes, 15 rue de \\ I'Ecole de Médecine, Paris Cedex 06, France
}

It is well recognized that environmental conditions during development (i.e., before birth) contribute to programming for adult diseases. We have previously demonstrated in the rat that in utero exposure to maternal diabetes impairs renal development leading to a $30 \%$ reduction in nephron number. The aim of the present study was to assess long-term effects of in utero exposure to maternal diabetes on arterial blood pressure and renal function in rats at 6 and 9 months of age.

Diabetes was induced in Sprague-Dawley pregnant rats by intraperitoneal streptozotocin injection $(35 \mathrm{mg} / \mathrm{kg})$ on day 0 of gestation. Arterial blood pressure (BP) was measured using the tail-cuff plethysmography method. Rats were housed in metabolic cages for $24 \mathrm{~h}$ urine collection; blood samples were withdrawn from the tail. 24-h urinary creatinine clearance was calculated as an estimate of GFR and urinary protein excretion was measured.

At birth, the weights of offspring from control and diabetic mothers were similar. BP was higher in rats born from diabetic mothers than in control rats by about $20 \%$ at 6 months and by $30 \%$ at 9 months of age. Creatinine clearance was lower in offspring of diabetic mothers than in control rats by $30 \%$ at 6 months and $40 \%$ at 9 months. This decline in GFR suggests that glomerular lesions resulting from the compensatory renal adaptation that follows nephron loss were severe enough for functional exclusion of some glomeruli. In addition proteinuria was found to be two fold greater in rats issued from diabetic mothers of the two age groups.

In conclusion, in utero exposure to maternal diabetes induces hypertension and chronic kidney disease with renal failure in the offspring at adulthood. 
36

\section{A Chloride Channel with Properties of CLC-K2 in the Mouse Connecting Tubule}

\author{
A. Nissant, J. Teulon \\ UMR7134 CNRS-Université Pierre et Marie Curie, 15 rue \\ de l'Ecole de Médecine, Paris, France
}

The connecting tubule (CNT) is a heterogeneous segment interposed between the distal convoluted tubule and the collecting tubule, which comprises connecting and intercalated cells. In the present study, we investigated basolateral chloride channels in the mouse CNT, using the cell-attached and inside-out variants of the patch-clamp method.

Microdissected CNTs were isolated from collagenase-treated kidneys. The pipette solution contained (in $\mathrm{mM}$ ): $145 \mathrm{NaCl}, 1 \mathrm{CaCl} 2,1$ $\mathrm{MgCl} 2,10$ glucose and 10 HEPES at $\mathrm{pH}$ 7.4. The bath solution was similar except that it contained $5 \mathrm{mM} \mathrm{KCl}$ and $140 \mathrm{NaCl}$.

In cell-attached patches, we found a chloride-selective channel with a conductance of $10.6 \pm 0.9 \mathrm{pS}(\mathrm{n}=8)$ : the reversal potential significantly changed from $1.9 \pm 4.0 \mathrm{mV}$ in the control $(\mathrm{n}=8)$, to $25.7 \pm 1.2 \mathrm{mV}$ in the presence of $100 \mathrm{mM} \mathrm{Na}$-gluconate $(\mathrm{n}=4)$, whereas there was no significant change $(-1.1 \pm 2.0 \mathrm{mV}, \mathrm{n}=8)$ with $140 \mathrm{mM}$ NMDG-chloride. We estimated the influence of extracellular $\mathrm{Ca}^{2+}$ and $\mathrm{pH}$ on channel activity by measuring the $N P_{o}$ on separate patches. The $N P_{o}$ dramatically increased from $23 \pm 6(\mathrm{n}=11)$ with $1 \mathrm{mM} \mathrm{Ca}^{2+}$ in the pipette to $101 \pm 12(\mathrm{n}=10)$ with $5 \mathrm{mM} \mathrm{Ca}{ }^{2+}$. The $N P_{o}$ also significantly increased with extracellular $\mathrm{pH}$, from $26 \pm 7(\mathrm{n}=13)$ at $\mathrm{pH} 7.0$ to $71 \pm 12$ at $\mathrm{pH} 7.8(\mathrm{n}=12)$. The anionic selectivity was investigated quantitatively in the excised configuration and showed the relative permeability sequence: $\mathrm{Cl}^{-} \quad(1)>\mathrm{I}^{-} \quad(0.77 \pm 0.08)>\mathrm{NO}_{3}{ }^{-}$ $(0.56 \pm 0.09) \sim \mathrm{Br}^{-}(0.44 \pm 0.07)>\mathrm{F}^{-}(0.17 \pm 0.04)(\mathrm{n}=3-6)$.

The properties of the channel appear similar to a previously reported $\mathrm{Cl}^{-}$channel in the DCT (Lourdel et al., J Gen Physiol 2003; 121:287-300) and are compatible with the currently known properties of the ClC-K channels (Estevez et al., Nature 2001;414:558-561).

\section{7}

\section{Increased Expression of Type B Monoamine Oxydase in the Proximal Tubule of Rats with Type I Diabetes}

\author{
C. Ordener', M.H. Seguelas ${ }^{1}$, D.I. Cabou, C. Baradat ${ }^{1}$, \\ H. Lulka², J.M. Lerme², J.-P. Girolami, A. Parini ${ }^{1}$
}

Pharmacologie et Physiopathologie Rénale, ${ }^{1}$ INSERM U388, ${ }^{2}$ FFR 31, CHU Rangueil Bat 3, Avenue J Poulhes, BP84225, Toulouse Cedex, France

Type I diabetes mellitus, also known as insulin-dependent diabetes, is a metabolic disease characterized by autoimmune destruction of the $\beta$ cells of the pancreas. End-stage renal failure is one of the major complications of diabetes. Studies on animals and humans suggest a role for reactive oxygen species (ROS) in the physiopathology of diabetic complications. However, the mechanisms responsible for intracellular ROS accumulation remain poorly defined. The kidney contains large amount of monoamine oxydase (MAOs) A and B, two mitochondrial enzymes involved in degradation of biogenic amines (noradrenaline, serotonine, dopamine). During substrate degradation, MAOs generate large amount of hydrogen peroxide $\left(\mathrm{H}_{2} \mathrm{O}_{2}\right)$. In the present study we report that the activity and expression of MAO-B in the renal cortex was strongly increased in a model of streptozotocininduced diabetes in rat. This rise was restricted to the proximal tubule, as we did not observe any change in glomeruli, or in the liver used as a reference organ. Insulin treatment restored normoglycemia and reversed the observed changes in MAO-B activity.

These results suggest that insulin-dependent diabetes induces tissueand cell-specific regulation of MAO-B. The increase in renal MAO-B activity may participate to ROS overproduction observed during the development of diabetic nephropathy. Based on these results, it is conceivable that MAO-B may represent a new pharmacological target for the prevention or treatment of renal failure associated with diabetes.

38

A Slo2.2 Type, Na1-Activated, K1 Channel in the Basolateral Membrane of Mouse Thick Ascending Limb

\author{
M. Paulais, S. Lachheb, J. Teulon \\ UMR7134, 15 rue de l'Ecole de Médecine, \\ Paris Cedex 06, France
}

This study investigates the presence and properties of $\mathrm{Na}^{+}$activated $\mathrm{K}^{+}$channel $\left(K_{N a}\right)$ in mouse epithelial renal cells. Using realtime PCR on extracts of microdissected nephron segments, Slo2.2 mRNA, encoding for $K_{N a}$ channel in excitable cells, was found to be expressed in medullary and cortical thick ascending limbs of Henle's loop and to a much lesser extent in distal convoluted tubule. Patchclamp analysis revealed the presence of a large conductance $\mathrm{K}^{+}$channel in the basolateral membrane of medullary and cortical thick ascending limbs. The channel was highly $\mathrm{K}^{+}$selective $\left(\mathrm{P}_{\mathrm{K}} / \mathrm{P}_{\mathrm{Na}} \sim 20\right)$. Conductance ranged 140 to $180 \mathrm{pS}$ with sub-conductance levels, and the current/voltage relationship displayed a $\mathrm{Na}^{+}$-dependent inward rectification. Channel activity strongly increased with internal $\mathrm{Na}^{+}$ concentration with an $E C_{50}$ of $30 \pm 1 \mathrm{mM}$ and a Hill coefficient of $4 \pm 0.5$. Channel activity was unaltered by internal ATP and $\mathrm{pH}$, but clearly decreased with an increase in internal $\mathrm{Ca}^{2+}$

We conclude that the basolateral membrane of thick ascending limb is endowed with a $\mathrm{Na}^{+}$-activated, large conductance $\mathrm{K}^{+}$channel, closely resembling the cloned Slo2.2 channel, and $K_{N a}$ channels previously described in native excitable cells.

\section{9}

\section{Calpains are Involved in the Development of Glomerulonephritis}

\section{J. Peltier', J. Perez'1, A. Bellocq 1 , S. Doublier ${ }^{2}$, L. Baud $^{1}$ \\ ${ }^{1}$ INSERM U702, Paris, France; ${ }^{2}$ CERMS, Turin University, Italy}

Calpains are ubiquitous intracellular $\mathrm{Ca}^{+}$-dependent cysteine proteases involved in inflammation and ischemia processes. The aim of this study was to determine the role of these enzymes in the development of 
glomerulonephritis, by measuring their expression and activity in the kidney, and by assessing their importance in the development of glomerular injury and tubulo-interstitial inflammation in experimental anti-glomerular basement membrane (GBM) nephritis in the mouse.

C57BL6 mice were sacrificed 3 and $24 \mathrm{~h}$ after the intravenous injection of anti-GBM antiserum. Calpain proteins were detected in renal tissue by Western blotting. Calpain enzymatic activity was measured by both spectrofluorometry and identification of a $150 \mathrm{kDa}$ breakdown product of spectrin specifically produced by calpains. Nephrin expression was evaluated by immunohistochemistry in vitro on human podocytes and in vivo. Concentrations of MCP-1 were measured by ELISA.

Calpain expression was increased in renal tissue of mice a few hours after the injection of anti-GBM antiserum. Western blot analysis of $150 \mathrm{kDa}$ spectrin breakdown product showed that these calpains were in an active form. Simultaneously, calpains were excreted in an active form in urine. The presence of similar amounts of active calpains in urine of mice invalidated for the podocin gene demonstrated that the urinary calpain excretion resulted from an injury of the glomerular filtration barrier rather than from the inflammatory process. Urinary excretion of calpains might also result from tubular secretion, as they appeared in the supernatant of cultured tubular epithelial cells exposed to albumin. In turn, excreted calpains would contribute to the injury of the glomerular filtration barrier and to the development of peritubular inflammation, since they were shown in vitro to induce the cleavage of nephrin on the surface of podocytes and to enhance MCP-1 secretion by tubular epithelial cells exposed to albumin, respectively.

In conclusion, calpains promote glomerular and tubulo-interstitial injuries in glomerulonephritis.

\section{0 \\ Dissociation between Renal Hemodynamics and Histopathology during Nitric Oxide Deficiency}

\author{
S. Placier, M. Flamant, J.J. Boffa, C. Chatziantoniou, \\ J.C. Dussaule \\ INSERM U702, Paris, France
}

To evaluate the role of blood pressure (BP) on renal lesions during nitric oxide (NO) deficiency, rats were treated with L-NAME $(20 \mathrm{mg} / \mathrm{kg} / \mathrm{d})$. After 4 week, systolic BP reached $170 \mathrm{mmHg}$ and kidneys displayed glomerular lesions associated with a ten- and three-fold increase of proteinuria and creatininaemia, respectively, compared to controls. Thereafter, L-NAME treatment was combined with losartan $(20 \mathrm{mg} / \mathrm{kg} / \mathrm{d})$, an AT1 antagonist, or with vehicle for an additional period of 4 week. Losartan significantly reduced proteinuria and creatininaemia, and improved glomerular morphology, without altering BP.

In another set of experiments, the same protocol was performed with higher doses $(50 \mathrm{mg} / \mathrm{kg} / \mathrm{d})$ of L-NAME that induced tubulo-interstitial (TI) lesions. Sub-pressor doses of losartan $(30 \mathrm{mg} / \mathrm{kg} / \mathrm{d})$ did not modify TI lesions and hypertension $(168 \pm 25 \mathrm{mmHg})$ but allowed a significant regression of ischemic glomerular lesions. In parallel, renal blood flow (RBF) that was decreased by L-NAME after 4 week $(3.4 \pm 1.0 \mathrm{ml} / \mathrm{min})$ was improved by Losartan $(5.1 \pm 1.1 \mathrm{ml} / \mathrm{min} ; \mathrm{p}=0.05)$.

In conclusion, inhibition of the local effects of angiotensin II alleviates the fall of RBF consecutive to NO deficiency and reduces the morphological and functional lesions of glomeruli, independently of the changes in BP. In contrast, TI lesions are not correlated with the level of RBF and they do not regress with blockade of AT1 receptors when rats remain hypertensive.

In conclusion, in rats treated with high doses of L-NAME, inhibition of the local effects of angiotensin II ameliorates the fall of $\mathrm{RBF}$ in the setting of NO deficiency and reduces the morphological and functional lesions of glomeruli independent of changes in BP. In contrast, TI lesions do no correlate with levels of RBF and do not regress with the blockade of AT1 receptors when rats remain hypertensive.

\section{1 \\ UCP-2 Limits the Development of Hypertensive Renal Sclerosis without Modulation of Angiotensin II-Induced High Blood Pressure}

\author{
N. Sabaa1 , B. Miroux², T.M. Coffman ${ }^{3}$, D. Ricquier ${ }^{2}$, \\ J.-C. Dussaule ${ }^{1}$, P.-L. Tharaux ${ }^{1}$ \\ ${ }^{1}$ INSERM U702, Hôpital Tenon-75020 Paris, ${ }^{2}$ CNRS UPR \\ 9078, Faculté de Médecine Necker-Enfants Malades, \\ 75730 Paris cedex 15, France; ${ }^{3}$ Division of Nephrology, \\ Duke University Medical Center, Durham, N.C., USA
}

Uncoupling Protein-2 (UCP-2) belongs to a family of mitochondrial protein that promotes respiratory activity by allowing protons pumped by the respiratory chain to return into the mitochondrial matrix without ATP synthesis. Therefore, possible other functions include control of Reactive Oxygen Species (ROS) production by mitochondria and regulation of fatty acid oxidation. Previous studies have indicated that certain G protein-coupled receptor (GPCR) agonists, and in particular Angiotensin II (AII), stimulate generation of ROS through plasma membrane associated NADPH oxidases, thereby leading to tissue remodeling. In the present study, we hypothesized the involvement of mitochondria and UCP-2 in the pathogenesis of renal injury associated with AII chronic infusion. We took advantage of the UCP-2-/- mouse model. In the basal state, systolic blood pressures (SBP) were normal and comparable in UCP-2-/mice compared to controls, $(108 \pm 5$ vs. $105 \pm 7 \mathrm{mmHg}$, respectively). Then chronic studies were performed by using subcutaneous infusion of AII. The rise in SBP $(+45 \mathrm{mmHg}$ on day $14,+60 \mathrm{mmHg}$ on day 28) and survival (4/10 and $6 / 10$ in UCP-2 $-/-$ and $\mathrm{UCP}-2+/+$ respectively on day 28 ) were similar in both groups. Over the same periods, albuminuria was higher in UCP-2-/- mice from day $8(229 \pm 57$ vs. $92 \pm 29 \mathrm{~g} / \mathrm{mol}$ creatinine, $\mathrm{p}<0.01)$ to day 28 $(414 \pm 105$ vs. $131 \pm 50 \mathrm{~g} / \mathrm{mol}$ creatinine, $\mathrm{p}<0.01)$. Consistently, AII-treated UCP-2-/ - mice exhibited more severe glomerulosclerosis than their controls $(p<0.05)$. These data suggest that activation of renal UCP-2 during hypertension limits the development of renal injury. This effect might be due to a modulation of ROS generation that has only been demonstrated in macrophages to date. UCP-2 function may unravel the role of mitochondria as an unexpected pathway used by AII receptors to limit renal injury. 


\section{2 \\ Progression of Nephrosclerosis Involves EGF Receptor: Contrasting Roles for Epiregulin and TGF- $\alpha$ in Hypertension}

\author{
N. Sabaa', M. Ciroldi', M. Flamant ${ }^{1}$, D. Lee ${ }^{4}$, P. Ruiz², \\ D. Threadgil/4, T.M. Coffman ${ }^{3}$, J.-C. Dussaule1, P.-L. Tharaux ${ }^{1}$ \\ ${ }^{1}$ INSERM U702, Hopital Tenon, Paris, France; ${ }^{2}$ Department \\ of Pathology, University of Miami, USA; ${ }^{3}$ Division of \\ Nephrology, Duke University Medical Center, Durham; \\ ${ }^{4}$ Department of Genetics, University of North Carolina, \\ Chapel Hill, N.C., USA
}

We have previously shown that endothelin and angiotensin II (Ang II) promote arterial and glomerular collagen synthesis through recruitment of MAPK/ERK activity by transactivation of EGF receptor. However, the relevant EGFR ligands produced in the kidney during hypertension are not known. Several growth factors have been identified that signal through the EGFR including TGF- $\alpha$ and Epiregulin (Ereg). To address the role of EGFR in chronic renal injury, we used homozygous mice with the waved-2 (wa-2) mutation that alters the tyrosine kinase activity of EGFR by $80 \%$ and normal age-matched males. We previously showed that wa- 2 mice have less hypertension, reduced albuminuria and are protected against nephrosclerosis after L-NAME administration. Nevertheless, we were unable to detect HB-EGF in kidneys by immunostaining. However, we found marked TGF- $\alpha$ staining in renal tubules. In Ang II-dependent hypertension with severe nephrosclerosis, wa- 2 mice, TGF- $\alpha$-deficient mice and Ereg-deficient mice were accordingly studied. Survival after 28 days was higher in waved- 2 mice than in their controls, with $50 \%$ less albuminuria and glomerulosclerosis. TGF- $\alpha$ expression was enhanced in the kidneys from sick animals. Ang II also stimulated Ereg gene transcriptional activity. Ereg-/- mice with similar high systolic blood pressure than Ereg $+/+$ mice displayed less vascular and renal damage. By contrast, TGF- $\alpha$ deficient mice displayed marked microalbuminuria and renal damage as their controls. Our data reveal the role of EGFR tyrosine kinase in two distinct hypertensive models and the contrasting roles of EGFR ligands in the development of hypertensive nephrosclerosis.

\section{3}

\section{Acid pH Enhances the Stability of the Na-K(NH4)-2CI Cotransporter (BSC1/NKCC2) mRNA via $\zeta$-Crystallin/NADPH: Quinone Reductase ( $\zeta$-CRYS) Protein}

\section{Szutkowska, Z. Karim, M. Bichara \\ INSERM U426, Faculté de Médecine Xavier Bichat, 16 rue Henri Huchard, Paris Cedex 18, France}

It has been shown that both metabolic acidosis and in vitro incubation in an acid medium increase the expression of BSC1 mRNA and protein in the rat MTAL ( $J$ Biol Chem 1998;273:33691-91). Furthermore, acid $\mathrm{pH}$ increases the BSC1 mRNA abundance by enhancing the stability of the mRNA by acting on its 3 '-UTR region ( $\mathrm{J}$ Am Soc Nephrol 2003;14:2229-2236). Finally, it is known that
$\zeta$-CRYS is the protein responsible for the stabilizing effect of acid $\mathrm{pH}$ on the mitochondrial glutaminase mRNA of the proximal tubule (Am J Physiol Renal Physiol 2001;281:F381-F390). In the present work, we used a suspension of rat MTAL fragments and an immortalized mouse MTAL cell culture to assess the mechanism of the acid $\mathrm{pH}$ effect on BSC1 mRNA. A specific antibody anti- $\zeta$-CRYS and a $\zeta$-CRYS cDNA have been provided by N. Curthoys. We have found that (1) the $\zeta$-CRYS protein is expressed in the cytoplasm of both preparations (western blot experiments). (2) Incubation at $\mathrm{pH} 7.10$ vs. $\mathrm{pH} 7.40$ enhances by $\sim 50 \%$ the $\zeta$-CRYS protein abundance in the cell culture $(P<0.003)$. (3) Co-transfection by $\zeta$-CRYS and BSC1 cDNAs enhances the BSC1 mRNA abundance in cells transfected with the wild type BSC1 cDNA $(P<0.003)$ but not in cells transfected with the BSC1 cDNA in which the $3^{\prime}$-UTR region was deleted. We conclude that acid $\mathrm{pH}$ stabilizes the BSC1 mRNA by augmenting the $\zeta$-CRYS protein abundance, and that $\zeta$-CRYS prevents the BSC1 mRNA degradation by acting on its $3^{\prime}$-UTR region that is AU-rich.

These data may explain the increased MTAL transport of $\mathrm{NH}_{4}{ }^{+} / \mathrm{NH}_{3}$ in response to metabolic acidosis, which should contribute to increased urinary acid excretion during metabolic acidosis.

\section{4 \\ Androgens Act as Antagonists of the Mineralocorticoid Receptor to Inhibit Aldosterone-Stimulated $\mathrm{Na}^{+}$Absorption in Renal Collecting Duct Cells}

\author{
A.-N. Takeda, G.M. Pinon, M. Bens, J. Fagart, \\ M.-E. Rafestin-Oblin, A. Vandewalle \\ INSERM U478, Faculté de Médecine Xavier Bichat, \\ BP416, Paris Cedex 18, France
}

Aldosterone binds to the mineralocorticoid receptor (MR) and exerts fine control of $\mathrm{Na}^{+}$absorption in renal collecting duct cells (CCDs). Many other natural or synthetic steroids can also bind to MRs to exert agonist or antagonist activity. Here we investigate whether androgenic hormones are efficient MR ligands in CCDs. Testosterone (T), dihydrotestosterone (DHT), R1881, a synthetic androgen agonist, and cyproterone acetate (CPA), a potent synthetic antiandrogen, all bind to the MR. Whereas these androgens and CPA did not activate the MR transiently expressed in human embryonic kidney HEK 293T cells, they did antagonize (R1881 > DHT > $\mathrm{T}>\mathrm{CPA}$ ) aldosterone-induced MR trans-activation activity. Short-circuit current $\left(\mathrm{I}_{s c}\right)$ experiments revealed that $10^{-5} \mathrm{M}$ T, DHT or $\mathrm{R} 1881$, as well as CPA, partially or totally prevented the rise in amiloride-sensitive component of $\mathrm{I}_{s c}$ caused by aldosterone in mouse mpkCCD $\mathrm{cl}_{4}$ cells. In contrast, androgens and CPA had no effect on the stimulated- $\mathrm{I}_{s c}$ elicited by the specific glucocorticoid agonist RU26988. Docking analyses using a three-dimensional model generated from the crystal structure of the ligand-binding domain of a mutant $\mathrm{MR}\left(\mathrm{MR}_{\mathrm{L} 810}\right)$, revealed that the $17 \beta$-hydroxyl group of androgens are unable to contact Asn770. Moreover, androgens inhibited the 18-oxo-18-vinylprogesterone-induced activity of the mutant $\mathrm{MR}_{\mathrm{A} 770}$, in which Ala was substituted for Asn at position 770.

These findings indicate that the antagonist property of androgens is attributable to the absence of contact with Asn770, and suggest 
that androgens may act as potent MR antagonists in inhibiting the absorption of $\mathrm{Na}^{+}$elicited by aldosterone in renal cortical collecting duct cells.

\section{5 \\ Interaction of Urea Secretion and Metabolic Osmole Production (Mop) in the Urinary Concentrating Mechanism: Exploration in a 3D Model of the Renal Medulla}

\section{S.R. Thomas}

LaMI UMR CNRS 8042, 523 Place des terrasses de

I'Agora, Evry, France

We have adapted our 3-D mathematical model of the renal medulla to explore the possible contributions of two features for which a role in the urine concentrating mechanism has been suggested, namely, urea secretion along the proximal straight tubule, and metabolic osmole production (MOP) within the inner medulla (IM).

(1) The idea of urea secretion into the tubular fluid arises naturally from the straightforward deduction that, given published measurements of fractional delivery of urea (FDu) at points along the nephron accessible to in vivo micropuncture, the high observed rates of fractional excretion of urea (FEu) $(30 \%$ to $>100 \%$, depending on species and diet) can only be explained by postulating secretion of urea into tubular fluid somewhere along the loop of Henle. Several published discursive explanations of how the added urea would affect both urine concentration and urea balance are difficult to reconcile with reported permeabilities and micropuncture results, with the distribution of known urea transporters, and with inter-species differences of medullary anatomy.

(2) We showed in studies using simpler medullary models that lactate production by anaerobic glycolysis (AG) (due to the constitutive hypoxia of the inner medulla) may play an important role in the urine concentrating mechanism. This is first exploration of this mechanism in a $3 \mathrm{D}$ model.

Implemented at face value in our model, the urea secretion modes suggested in the literature do, in fact, better account for the high observed values of $\mathrm{FEu}$, but at the cost of reduced, rather than increased, concentrating ability. By adjusting certain permeability values, we arrive at several possible solutions to this apparent conflict. Furthermore, inclusion of MOP greatly improves the agreement of model predictions with experimental observations, and the present 3 -D exploration of this feature resolves some issues left open in the earlier and simpler modelling studies.

\section{6}

\section{Reduced Proximal Tubular Endocytosis Induced by HMG-COA Inhibitors}

\section{A. Verhulst, P.C. D'Haese, C. Brown, M.E. De Broe \\ Department Nephrology-Hypertension, University of Antwerp, Universiteitsplein 1, Wilrijk, Belgium}

Statins, by their ability to inhibit 3-hydroxy-3-methylglutaryl coenzyme A (HMG-CoA) reductase, are potent inhibitors of cholesterol biosynthesis and are widely used to lower serum LDL-cholesterol. However, there have been reports of proteinuria occurring in association with statin treatment (Lancet 1990;337:864). Using primary cultures of human tubular kidney cells, we investigated whether this complication could be the result of a reduced protein uptake in the proximal nephrons.

Tubular epithelial cells were isolated from normal human kidney tissue. Confluent cultures of proximal tubular (PT), distal tubular and collecting duct cells were incubated with simvastatin (concentrations up to $50 \mu \mathrm{M}$ ), pravastatin or rosuvastatin (concentrations up to $500 \mu \mathrm{M}$ ) for $16 \mathrm{~h}$. Protein uptake was measured by incubating these cultures for $1 \mathrm{~h}$ with fluorescein (FITC) labelled albumin. After extensive rinsing, the cells were lysed and the intracellular fluorescence was measured using spectrofluorometry to quantify the albumin uptake (per g total protein) or by flowcytometry to assess the uptake selectively into PT cells (fluorescently stained for leucineaminopeptidase, a specific PT cell marker). In order to get a better insight into the mechanism underlying these observations, mevalonate $(100 \mu \mathrm{M})$, the product of HMG-CoA reductase activity, was added to the cultures to check whether this would be able to prevent the statin induced effects. Finally, cholesterol synthesis and cell viability was measured after statin treatment.

Flowcytometric analysis revealed that albumin uptake took place selectively in PT cells. A significant $(* p<0.05)$ inhibition of albumin uptake was noted for the 3 statins and each had a similar degree of effect on the uptake. In the presence of simvastatin $(0.1,1,10$, $50 \mu \mathrm{M})$ the albumin uptake was reduced to respectively $74^{*} \pm 32$, $70^{*} \pm 28,64^{*} \pm 28$ and $57^{*} \pm 24 \%$ (mean \pm SD) of control values. For pravastatin $(1,10,100$ and $500 \mu \mathrm{M})$, albumin uptake was reduced to $74^{*} \pm 28,73^{*} \pm 30,56^{*} \pm 25$ and $46^{*} \pm 27 \%$ of control values and for rosuvastatin tested at the same concentrations, the reductions were to $72^{*} \pm 30,66^{*} \pm 27,70^{*} \pm 39$ and $56^{*} \pm 19 \%$ of the control values. Furthermore, statins induced dramatic inhibition of cholesterol synthesis without loss of cell viability. Finally, mevalonate completely prevented the effect of the statins.

These results indicate that statins by inhibiting HMG-CoA reductase may inhibit protein uptake by the proximal nephrons, which in vivo may turn into tubular type proteinuria. Currently, uptake and transport of statins in PT is being studied.

47

\section{Lipocalin: Mediator of Nephron Reduction}

A. Viau' ${ }^{1}$, M. Burtin' 1 , K. Mori², J. Barasch ${ }^{2}$, F. Terzi ${ }^{1}$

${ }^{1}$ INSERM U426 - Hôpital Necker - 149 rue de Sèvres -

75015 Paris, France; ${ }^{2}$ Columbia University (NYC), N.Y., USA

Chronic renal diseases (CRD) are characterized by a progressive decline of renal function, which occurs irrespective of the cause of the renal damage once a critical number of nephrons has been lost. The mechanisms underlying this process are poorly understood.

In order to identify novel mediators that may contribute to renal disease progression, we use a known-gene cDNA microarray (5.579 genes) to compare the mRNA expression profiles in remnant kidneys from two strains of mice that we previously showed differently react to nephron reduction: one strain (C57B16) undergoes compensatory growth alone, whereas the other $(\mathrm{FVB} / \mathrm{N})$ additionally develops 
severe renal lesions. Sixty days after nephron reduction, we identify 79 genes with altered levels of expression: 34 genes were upregulated and 46 genes were reduced in $\mathrm{FVB} / \mathrm{N}$ mice as compared to $\mathrm{C} 57 \mathrm{~B} 16$ ones. Using Gene Ontology annotations, these genes were classified by functions related to cell proliferation and cell cycle, transcription, transport and metabolism. Real-time RT-PCR analysis was used to confirm microarray analysis of 20 genes with altered expression.

We next focused on the most upregulated gene ( 9 folds): $l c n 2$, that encodes for lipocalin $24 \mathrm{p} 3$, a small secreted polypeptide of the lipocalin superfamily, involved in the iron pathway. This gene has recently been shown to participate to renal recovery after an acute injury, but its induction after nephron reduction was novel to CRD field. The marked upregulation of lipocalin $24 \mathrm{p} 3 \mathrm{mRNA}$ and protein in remnant kidneys of $\mathrm{FVB} / \mathrm{N}$ mice during lesion development was confirmed by quantitative real-time RT-PCR and western blot, respectively. By immunohistochemistry, we demonstrated that the protein is expressed predominantly in proximal tubules. Furthermore, we observed that lipocalin overexpression is associated to iron deposition in remaining nephrons of FVB/N nephrectomized mice.

In conclusion, our data identified several novel genes that may be important in progression of chronic renal diseases. Among these genes, lipocalin $24 \mathrm{p} 3$ might play a key role, by favoring cell proliferation and/or iron accumulation. Future functional studies will allow us to verify this hypothesis.

\section{8 \\ Thymosin $\beta 4$ a New Gene Involved in Renal Development: Retinoids Regulation}

\section{Viltard, I. Guinobert, D. Piquemal, M. Lelièvre-Pegorier \\ INSERM U652, Institut Biomédical des Cordeliers, 15 rue de l'Ecole de Medecine, Paris Cedex 06, France}

Kidney development involves a wide variety of developmental processes including budding, reciprocal interactions, mesenchymalepithelial transitions, branching and morphogenesis. All these processes require a lot of genes expressed in a sequential manner. In order to unravel the genetic basis of kidney development it is necessary to identify all the genes expressed during these processes. In a previous work, we have established the mouse embryonic kidney transcriptome (E14) using a serial analysis of gene expression assay adapted for downsized extract (SADE). The comparison of this transcriptome to the adult one allowed us to highlight some candidate genes involved in kidney development. Among them, we identified Thymosin $\beta 4$ (T $\beta 4$ ) the most highly differentially expressed gene between fetal and adult kidney, known to play a critical role in cellular proliferation, differentiation and cell migration.

In the present work, we analyze the T $\beta 4$ spatio-temporal expression pattern during renal development and its regulation by retinoids since it is well known that vitamin A through its active form retinoic acid (RA) modulates nephrogenesis in vivo and in vitro. Results show that T $\beta 4$ expression pattern changed dynamically during metanephric development: the transcript expression detected at E12, increase gradually up to a maximal level at E18 when nephrogenesis is very active and then decrease to reach very low level in adult kidney. In situ hybridisation was used to localise mRNA T $\beta 4$ in developing mouse metanephroi. Mainly, at E18 we observed a strong expression of T $\beta 4$ in non mature glomeruli (i.e. S-shaped bodies) and a decreased expression in more mature glomeruli. Concerning regulation of T $\beta 4$ expression by retinoids, we have observed that the addition of $100 \mathrm{nM}$ RA in metanephroi cultured for 2, 4 or 6 days induced no modification of T $\beta 4$ expression after 2 days of culture but a strong increase after 4 days, an increase which remained high after 6 days.

Together these results suggest that T $\beta 4$ plays an important role in early nephron formation and in its regulation by retinoids.

49

\section{A Cellular Metabolomic Study of the Ammoniagenic Effect of Valproate in Human Precision-Cut Kidney-Cortex Slices}

\author{
A. Vittorelli, C. Gauthier, C. Michoudet, G. Martin, \\ G. Bavere/ \\ Laboratoire de Physiopathologie Métabolique et Rénale, \\ Institut National de la Santé et de la Recherche Médicale, \\ UMR 499, Faculté de Médecine R.T.H. Laennec, \\ Université Claude-Bernard-Lyon 1, Lyon, France
}

Glutamine, whose metabolism plays a major role in systemic acidbase homeostasis, is taken up at various rates from the circulating blood by the human kidney under various circumstances. Not only because of the limited availability of human renal tissue but also in part because of the lack of adequate cellular models, the mechanisms regulating the renal metabolism of this amino acid in humans have been poorly characterized. Therefore, given the renewed interest in their use, human precision-cut renal cortical slices were incubated in Krebs-Henseleit medium with $2 \mathrm{mM}$ unlabeled or ${ }^{13} \mathrm{C}$-labeled glutamines. After incubation, substrate utilization and product formation were measured by enzymatic and NMR spectroscopy methods. Glutamate accumulation tended to plateau, but glutamine removal and ammonia, alanine and lactate production, as well as flux through glutamate dehydrogenase, increased to various extents with time for up to 4 hours of incubation, indicating the metabolic viability of the slices. Valproate, a stimulator of renal glutamine metabolism, markedly and in a dose-dependent fashion increased ammonia production. With [3${ }^{13} \mathrm{C}$ ]glutamine as substrate, and in the absence and the presence of valproate, $\left[{ }^{13} \mathrm{C}\right]$ glutamate, $\left[{ }^{13} \mathrm{C}\right]$ alanine and $\left[{ }^{13} \mathrm{C}\right]$ lactate accounted for $81 \%$ and $96 \%, 34 \%$ and $63 \%, 30 \%$ and $46 \%$ of the glutamate, alanine and lactate accumulations measured enzymatically, respectively.

These results demonstrate that, although endogenous metabolism substantially operates in the presence of glutamine, human precisioncut renal cortical slices are metabolically viable and strongly respond to the ammoniagenic effect of valproate. Thus, this experimental model is suitable for metabolic and pharmaco-toxicological studies. 
50

\section{Tubular Cell Proliferation in the Healthy Rat Kidney Relies on Differentiated Cells}

\author{
A. Vogetseder, A. Karadeniz, B. Kaissling, M. Le Hir \\ Institute of Anatomy, Winterthurerstrasse Zurich, \\ Switzerland
}

We searched for morphological evidence that might support the hypothesis that stem cells are responsible for renal tubular cell proliferation. The rationale of the study was that if proliferation relies on progenitors, then mitotically active cells should be less differentiated than other tubular cells. In addition, as the retention of the thymidine analog BrdU has been the approach employed up to now to identify stem cells in the kidney we characterized BrdU-retaining tubular cells by imunofluorescence.

Kidneys of 6 weeks old rats were fixed by perfusion. Cycling cells, identified by mitotic figures or the expression of the proliferating cell nuclear antigen (PCNA) were examined by light- and electron microscopy as well as by immunofluorescence for four differentiation markers. For the detection of label-retaining cells, newborn rats were injected with BrdU. Eight, 14 and 35 weeks after BrdU injection the kidneys were examined by immunofluorescence for BrdU and the same four differentiation markers mentioned above. All cycling cells showed the same degree of differentiation compared to non-cycling cells. The vast majority of the detected label-retaining cells were differentiated.

We conclude that cycling cells in tubules of the healthy kidney are differentiated and that the retention of label is not a criterion to identify stem cells in renal tubules.

\section{1}

\section{RhBG and RhCG Behave as Ammonia Transporters in Epithelial Cells}

\author{
N. Zidi-Yahiaoui, I. Mouro-Chanteloup, A.M. d'Ambrosio, \\ C. Lopez, P. Gane, C. Le Van Kim, J.P. Cartron, Y. Colin, \\ P. Ripoche \\ INSERM U665, INTS, 6 Rue Alexandre Cabanel, Paris, France
}

The human Rh (rhesus) proteins are members of the Amt/Mep/Rh superfamily identified in bacteria, yeasts, plants and animals. While $\mathrm{Rh}(\mathrm{CE} / \mathrm{D})$ and RhAG proteins are erythroid specific, RhBG and RhCG are expressed in organs involved in the transport and metabolism of ammonium, such as kidney and liver. We have recently shown that RhAG facilitates $\mathrm{NH}_{3}$ gas transport across the red cell membrane (Ripoche et al., PNAS 2004;101:17222-17227). In the current study, we have analyzed the functional properties of the non-erythroid RhBG and RhCG recombinant proteins when expressed in the kidney cell lines HEK293 and MDCK. The ammonium transport function was determined by monitoring intracellular $\mathrm{pHi}$ changes of cells submitted to methylammonium $\left(\mathrm{CH}_{3} \mathrm{NH}_{3}{ }^{+}+\mathrm{CH}_{3} \mathrm{NH}_{2}\right)$ or ammonium $\left(\mathrm{NH}_{4}{ }^{+}+\mathrm{NH}_{3}\right)$ gradients. This was done by stopped-flow analysis using an intracellular $\mathrm{pH}$-sensitive fluorescent probe. Rapid alkalinisation and acidification phases corresponding to influx or efflux of $\mathrm{NH}_{3}$, respectively, were observed. In transfectant cells expressing $\mathrm{RhBG}$ or RhCG, the kinetic rate constants of $\mathrm{pH}$ changes were 5 times greater and less sensitive to temperature than in parental cells. However, in the presence of a $\mathrm{CH}_{3} \mathrm{NH}_{2}$ gradient, kinetic rate constants are 5 to 7 times more rapid for RhBG than RhCG. Transport inhibition by $\mathrm{Hg}^{2+}$ confirmed that the facilitated transport of $\mathrm{NH}_{3}$ in recombinant cells is associated to RhBG and RhCG expression but not to some lipid bilayer alteration of the transfected cells. Cysteine to alanine mutant analysis, however, failed to target the residue(s) involved in inhibition.

Our results suggest that by facilitating $\mathrm{NH}_{3}$ transport across cell membranes, $\mathrm{Rh}$ glycoproteins, may represent the first family of gas channels identified in mammals. Additionally, differences in substrates accessibility between RhBG and RhCG might reflect their different localisation, basolateral or apical, in kidney epithelial cells (Zidi-Yahiaoui et al., Biochem J 2005, in press). 
Ackermann, D. 1

Bacic, D. 2

Bado, A. 22

Bakouh, N. 21

Baradat, C. 37

Barasch, J. 47

Barbier, O. 26

Baud, L. 20, 29, 39

Baudouin-Legros, M. 32

Baverel, G. 17, 49

Becker, J. 30

Becq, F. 32

Behr, L. 3

Belfodil, R. 31, 4

Bellocq, A. 29, 39

Bens, M. 13, 15, 44

Bensalem, N. 5, 8, 9, 32,

Biber, J. 2

Bichara, M. 43

Bize, V. 6

Blanchard, A. 7

Bloch-Faure, M. 12

Bodin, S. 17

Boffa, J.J. 40

Boghossian, M. 17

Borenstein, N. 3

Borot, F. 8

Boulkroun, S. 13, 22

Bourgeois, S. 12

Brasse-Lagnel, C. 30

Briet, M. 7

Brouillard, F. 8, 9, 24

Brown, C. 46

Buleon, M. 10

Burtin, M. 47

Buzoni-Gatel, D. 15

Cabou, D.I. 37

Calmont, A. 34

Cambillaud, M. 12

Capendeguy, O. 11

Caron, N. 16

Cartron, J.P. 12, 51

Chambrey, R. 12

Chang, C.T. 13

Chansel, D. 14
Chassin, C. 15

Chatziantoniou, C. 19, 40

Cheval, L. 1

Christensen, E.I. 27

Ciroldi, M. 14, 42

Cluzeaud, F. 15

Coffman, T.M. 14, 41, 42

Colin, Y. 12, 51

Conjard, A. 17

Cosijns, J.-P. 27

Cougnon, M. 26

Courtois-Coutry, N. 22

Curat, C. 19

d'Ambrosio, A.M. 51

Darche, S. 15

Davezac, N. 5, 32

De Broe, M.E. 46

Declèves, A.E. 16

Delage, H. 17

Deschênes, G. 18

Desvergnes, B. 29

Devuyst, O. 27

D'Haese, P.C. 46

Dossier, B.C. 25

Doublier, S. 39

Doucet, A. 1, 18

Dubois, Y.-C.X. 20

Ducroc, R. 22

du Merle, L. 15

Dussaule, J.-C 14, 19, 40, 41,42

Edelman, A. 5, 8, 9, 21, 24, 32

Eid, A. 17

Eladari, D. 12

Fagart, J. 44

Fajac, A. 5

Farman, N. 22

Favre, G. 18

Ferrier, B. 17

Filali, M. 7

Fischer, E. 34

Flamant, M. 19, 40, 42

Flamion, B. 16
Fouqueray, B. 29

Frangié, C. 20

Freund, N. 23, 35

Friedlander, G. 21

Fritsch, J. 8, 24

Froissart, M. 7

Fromont, G. 3

Gaeggeler, H.P. 25

Gailly, P. 27

Galmiche, L. 21

Gane, P. 51

Gauthier, C. 49

Geoffroy, V. 12

Girolami, J.-P. 10, 37

Gomez, A.-M. 14

Gonzalez-Nunez, D. 22

Gonzalez-Rodriguez, E. 25

Goolaerts, A. 33

Goossens, D. 12

Goujon, J.-M. 15

Grandchamp, B. 21

Gruber, A.D. 9

Gubler, M.-C. 27

Guinobert, I. 23, 35, 48

Guisan, B. 25

Halgand, F. 5

Haymann, J.-P. 20, 29

Hekmati, M. 3

Heudes, D. 29

Hinzpeter, A. 8, 9, 24

Horisberger, J.-D. 6, 11, 25

Houillier, P. 7, 12, 34, 35

Hummler, E. 13

Husson, A. 30

Imbert-Teboul, M. 1

Jackson, L.F. 14

Jacquillet, G. 26

Jeunemaitre, X. 7

Jouret, F. 27

Joye, E. 29

Kaissling, B. 2, 50

Karadeniz, A. 50
Karim, Z. 43

Laborde, K. 3

Lachheb, S. 28, 38

Laprévote, O. 5

Le Bouguénec, C. 15

Lee, D. 42

Lee, D.C. 14

Legrand, A. 16

Le Hir, M. 2, 50

Lelièvre-Pégorier, M. 3, 23, 34, 35, 48

Lerme, J.M. 37

Letavernier, E. 29

Le Van Kim, C. 51

Leviel, F. 12

Levillain, O. 30

L'Hoste, S. 4, 31

Lipecka, J. 5, 24, 32

Loffing, J. 18

Lopez, C. 51

Lourdel, S. 18

Lulka, H. 37

Martin, D. 26

Martin, G. 49

Martin, M. 17

Michoudet, C. 49

Mies, F. 33

Miroux, B. 41

Mori, K. 47

Mouro-Chanteloup, I. 51

Murer, H. 2

Mustel, A. 34

Namorado, M.C. 26

Nehiri, T. 35

Nissant, A. 18, 36

Nonclercq, D. 16

Norez, C. 32

Ollero, M. 8, 9

Ordener, C. 37

Paillard, M. 12

Parini, A. 37

Parvy, P. 30

\section{KARGER}

(C) 2006 S. Karger AG, Basel

Fax +41613061234

E-Mail karger@karger.ch

www.karger.com 
Paulais, M. 18, 28, 38

Peltier, J. 29, 39

Perez, J. 20, 29, 39

Picard, N. 12

Pinon, G.M. 44

Piquemal, D. 23, 48

Placier, S. 19, 40

Planelles, G. 21, 32

Poujeol, C. 4

Poujeol, P. 4, 26, 31

Prié, D. 21

Rabier, D. 30

Rafestin-Oblin, M.-E. 44

Ramirez-Gallardo, M.A. 22

Reyes, J.L. 26

Ribes, D. 34
Richard, S. 14

Ricquier, D. 41

Ripoche, P. 51

Rossert, J. 34

Rossier, B.C. 13

Rubera, I. 4

Ruiz, P. 42

Sabaa, N. 41, 42

Sariban-Sohraby, S. 33

Scheinman, S.J. 27

Schild, L. 13

Seguelas, M.H. 37

Sermet-Gaudelus, I. 5

Shlyonsky, V. 33

Siwiak, M. 24

Soultan, S. 4
Szutkowska, M. 43

Tack, I. 10

Takeda, A.-N. 44

Tauc, M. 4, 31

Techer, J. 30

Terzi, F. 47

Teulon, J. 13, 18, 28, 36, 38

Tharaux, P.-L. 14, 41, 42

Thomas, S.R. 45

Threadgill, D. 42

Tondelier, D. 5, 8, 9

Toubeau, G. 16

Vallée, B. 5
Vandermeersch, S. 14

Vandewalle, A. 13, 15, 44

Ventura, A.P. 5

Verhulst, A. 46

Viau, A. 47

Viltard, M. 23, 35, 48

Vittorelli, A. 49

Vogetseder, A. 50

Vogt, B. 1

Wagner, C.A. 2

Wahli, W. 29

Wiesinger, H. 30

Zhang, W. 20

Zidi-Yahiaoui, N. 51

Zielenkiewicz, P. 24 